\title{
Literacia histórica e história transformativa ${ }^{1}$
}

\section{Historical literacy and transformative history}

\author{
Peter Lee ${ }^{2}$
}

\begin{abstract}
RESUMO
A Educação Histórica, como a própria história, é uma conquista precária; é vulnerável a agendas políticas e educacionais que procuram mesclá-la com outras partes do currículo ou reduzi-la a um veículo para a cidadania ou valores comuns patrióticos. Se tivermos a expectativa de nos engajarmos em uma discussão séria na Educação Histórica em face destes desafios, devemos evitar lemas polares como "tradicional versus progressista", "centrado na criança versus centrado na matéria" e "habilidades versus conteúdo", que têm produzido muita confusão na literatura. Em particular, deve-se evitar falar de competências, com a sua infeliz concessão de licenças a convenientes e tolos currículos genéricos. A história é uma forma pública de conhecimento e o desenvolvimento de uma tradição metacognitiva, com as suas próprias normas e critérios. Há evidências que sugerem que a história é contraintuitiva e que entendê-la envolve a alteração ou até mesmo o abandono de ideias cotidianas que tornam o conhecimento do passado impossível. Consequentemente o ensino de história envolve o desenvolvimento de um aparato conceitual de segunda ordem que permite que a história siga em frente, em vez de imobilizá-la e, ao fazê-lo, abre a perspectiva de mudança de uma visão cotidiana da natureza e do estado do conhecimento do passado para uma de conhecimento histórico. Isto nos permite dar conta do que significa saber um pouco de história - um provisório conceito de literacia histórica - como um aprendizado de uma compreensão disciplinar da história, como a aquisição das disposições que derivam e impulsionam essa compreensão histórica e
\end{abstract}

DOI: $10.1590 / 0104-4060.45979$

1 Texto traduzido por Lucas Pydd Nechi, Doutorando em Educação do Programa de Pós-Graduação em Educação da Universidade Federal do Paraná, e Tiago Sanches, Professor e Pesquisador da Universidade da Integração Latinoamericana (UNILA).E-mails: lucaspyddnechi@ hotmail.com; tiago0683@hotmail.com

2 School of Arts and Humanities. University of London Institute of Education. London, England. 20 Bedford Way; London; United Kingdo; WC1H 0AL.E-mail: peter.lee11@talktalk.net 
como o desenvolvimento de uma imagem do passado, que permite que os alunos se orientem no tempo. Existem pesquisas para informar o debate sobre o primeiro componente, mas há pouco disponível para o segundo. Há um interesse atual considerável no terceiro componente, mas o debate centrou-se sobre a questão perene da "ignorância" das crianças, em vez de reconhecer que o problema é encontrar maneiras de permitir que os alunos adquiram passados históricos utilizáveis que não são histórias fixas. A obtenção de literacia histórica potencialmente transforma a visão de mundo de crianças (e de adultos) e permite ações até então - literalmente - inconcebíveis para eles. Entender a importância disto para o ensino da história significa abandonar hábitos de pensar com base em um presente instantâneo, em que uma forma de apartheid temporal separa o passado do presente e do futuro. Significa, também, desencaixotar as formas em que a história pode transformar como vemos o mundo. Tais transformações podem ser dramáticas em longas extensões ou mais localizadas e específicas. Elas podem mudar a forma como vemos oportunidades e constrangimentos políticos ou sociais, a nossa própria identidade ou dos outros, a nossa percepção das feridas e fardos que herdamos e a adequação das explicações das principais características do nosso mundo. Elas podem sugerir revisões constrangedoras do nosso entendimento e expectativas de como o mundo humano funciona. $\mathrm{E}$ elas podem nos ajudar a conhecer melhor o que não dizer. Literacia histórica envolve tratar o passado como uma ecologia temporal interconectada capaz de suportar uma gama indefinida de histórias, não apenas algo que usamos para contar a história que melhor se adapte aos nossos objetivos e desejos imediatos. Como outras formas públicas de conhecimento, a história é uma tradição metacognitiva que as pessoas têm lutado longa e duramente para desenvolver e ser capaz de praticar. É uma conquista frágil, a ser tratada com respeito e cuidado nas escolas.

Palavras-chave: literacia histórica; Educação Histórica; ensino de história.

\begin{abstract}
History Education, as history itself, is a precarious achievement; and it is vulnerable to political and educational schedules that try to mix it with other parts of the curriculum or reduce it to a medium for citizenship or common patriotic values. If we expect to engage in a serious discussion about History Education in view of these challenges, we should avoid polar opposite mottos as "traditional against progressive", "focused on the child against focused on the subject" and "skills against the contents", which have caused great confusion over literature. In particular, we should avoid
\end{abstract}


talking about competences, with their bad permission granted to convenient and foolish generic curricula. History is a public manner of knowledge and the development of a metacognitive tradition, with its own rules and criteria. There are evidences suggesting that history is counterintuitive, and that understanding it involves altering or even abandoning everyday ideas that make knowledge of the past impossible. Consequently, teaching history involves the development of a second-class conceptual tool that allows history to move forward, instead of making it pause, and making it, it offers the perspective of change of an everyday view of nature and of the state of knowledge of the past to the one in history knowledge. It allows us that we account for the meaning of knowing a little history - a provisional concept of historical literacy - as the learning of a disciplinary understanding of history, as the acquisition of the tools that cause and promote this history understanding, and how the development of an image from the past allows students to find their way in time. There are researches to inform the discussion about the first component, but there is little available to the second. There is a current considerable interest in the third component, but the discussion focused on the perennial matter of the children's "ignorance", instead of recognizing that the problem is to find ways that allow students to acquire usable historical pasts that are not fixed histories. Acquiring historical literacy potentially transforms the world vision of children (and of adults) and it permits actions so far - literally - inconceivable to them. Understanding its importance to the teaching of history means breaking habits of thinking based on an instantaneous present, in which a manner of time apartheid cuts the past from the present and from the future. It means also to unpack the manners in which history can transform how we see the world. Such transformations may be dramatic in large extents, or more located and specific. They may change how we see political or social opportunities and embarrassments, our own or others' identity, our perception of wounds and burdens we inherit, and the adequacy of the explanations of the main characteristics of our world. They may suggest embarrassing reviews of our understanding and expectations of how the human world operates. And they may help us to know better what not to say. Historical literacy involves dealing with the past as an interconnected temporal ecology that can support an indefinite range of stories, not only something that we use to tell the history that better adapts to our immediate objectives and wishes. Like other public manners of knowledge, history is a metacognitive tradition that people have struggled hard for a long time to develop and to be able to practice. It is a fragile achievement to be handled respectfully and carefully in the schools.

Keywords: historical literacy; History Education; teaching of history. 


\section{Introdução: a História como uma conquista frágil}

A Educação Histórica, como a liberdade de expressão, não pode nunca ser considerada como certa. Em alguns países europeus ela está atualmente sob a ameaça de agendas de cidadania e cívicas, por um lado, e agendas "de fusão", no outro ${ }^{3}$. O desejo de usar a história como um suporte para a coesão social ou mesmo o ressurgimento nacional parece prosperar em uma era da migração, da incerteza sobre as consequências do multiculturalismo e da busca por alguma base legítima de afirmação de valores "comuns". Enquanto isso, como a concorrência da China e da Índia aumenta, os políticos procuram novas maneiras de simplificar o currículo, em um esforço para assegurar que as competências exigidas pelas empresas possam encontrar espaço nas escolas. Apesar de se falar de uma "economia do conhecimento", a pressão sobre o currículo parece ser para as escolas treinarem uma mão de obra eficaz.

O primeiro desses desenvolvimentos leva a solicitações para o ensino de história ensinar "valores partilhados" por algum tipo habitual, geralmente a história nacional. À História é dado um papel importante, mas apenas como um veículo para as metas de cidadania. O paradoxo aqui é que, se a história é subordinada à cidadania, é provável que cesse de entregar precisamente o tipo de pensamento independente sobre o passado que faz da história uma parte crucial de uma sociedade democrática e aberta ${ }^{4}$. (Levado a sério, tal subordinação significaria que, se a história não conseguiu entregar os pontos de vista exigidos pela cidadania, as histórias contadas pela História teriam que ser alteradas para garantir que tenham êxito.)

O segundo desenvolvimento oferece a abertura de espaço no currículo através da "integração" da história em humanidades e cursos de ciência social. A justificativa para isso geralmente é feita pelo apelo à "eficiência" em um mundo competitivo, mas também pode evocar condescendência sobre o que os alunos podem lidar ou podem "necessitar" de autonomia e florescimento pessoal. Os últimos argumentos por vezes evidenciam hostilidade a "disciplinas" escolares 5 .

3 “Agendas Conflituosas" procuram fundir a história com uma variedade de outros "conteúdos" curriculares, desde a instrução religiosa e geográfica até a ciência social.

4 Ver o debate entre White e Lee, junto com a introdução de Shemilt, em Lee et al. (1992).

5 Observe que o argumento apresentado neste texto não é que a história não possa ser trabalhada com outras disciplinas, dentro ou fora da escola; tampouco não é que estudos interdisciplinares devam ser, por qualquer razão, jogados fora. Ao contrário, a pretensão é de que os estudantes poderiam adquirir uma compreensão da história (e de outra forma pública de conhecimento) antes dos estudos de interdisciplinaridade serem levados a efeito. Há alguma profunda condescendência na insistência de que os estudantes não "necessitam" de "conteúdos" escolares, invariavelmente 
A história é uma conquista frágil e o ensino de história (quando ele tenta ser histórico) pode ser ainda mais frágil. As questões levantadas por pressões atuais sobre o ensino de história demandam muito mais espaço do que está disponível em um breve artigo, principalmente porque os argumentos sobre os quais se baseiam são apenas a ponta de um iceberg de pressupostos mais profundos sobre a história, a aprendizagem e o desenvolvimento pessoal e social, e muito menos sobre a relação da educação com objetivos políticos e sociais. Em consequência, muito do que é dito aqui só pode sugerir algo do que está em jogo. No entanto, temos que começar por algum lado, e talvez essa contribuição será justificada se pudermos identificar algumas considerações chave. Mas primeiro temos de tentar esclarecer os termos do debate.

\section{Alguns "slogans" mal situados e polaridades}

Se o ensino de história é manter um ponto de apoio nas escolas, a rejeição de alguns "slogans" antigos é urgente. Especificamente, há três polaridades que há muito têm como ultrapassadas qualquer utilidade que algum dia poderiam ter tido. Quando aplicada à história, a justaposição de "tradicional versus progressiva", "centrada na criança versus centrada na matéria" e "habilidades versus conteúdo" torna difícil uma discussão produtiva e permite aos comentaristas evitarem uma reflexão séria.

\section{Um mito conveniente: "Tradicional" versus "Progressista"}

No Reino Unido, a noção de ensino de história "tradicional" tornou-se ligada com o que David Sylvester, fundador do influente e bem sucedido "Conselho de Escolas Projeto História 13-16", chamou de "a grande tradição". Esta versão do ensino de história, que é concebida como sendo uma espécie de "estado estável" antes das mudanças no final dos anos sessenta até meados dos anos setenta, é exemplificada no Conselho de Publicações de Educação desde o início do século XX e é retratada como tendo tratado a história como uma fonte de exemplos morais em uma história nacional dominada por "grandes

feita por pessoas que já aprenderam estes conteúdos na escola e continuam a operar com eles. Mas, aqui outra vez, requer-se cautela: não se tem a intensão de sacrificar a existência dos "conteúdos" escolares como eles aparecem em algum currículo em particular. As disciplinas que podem ou poderiam ser distinguidas como "conteúdos" escolares estão abertas ao debate. Será óbvio, contudo, que este texto inclua a história entre eles. 
homens". (SYLVESTER, 1996 apud DICKINSON, 2000, p. 87-8). Há, sem dúvida, alguma verdade nesta caracterização, mas, no entanto, oferece também uma versão simples do que estava acontecendo e sendo desenhado, como tantas vezes na história da educação, em pronunciamentos públicos e declarações oficiais, misturando uma série de questões diferentes.

Os objetivos dos professores de história são geralmente mais complexos e matizados do que os estabelecidos acima. Assim, ao mesmo tempo em que pode ter sido verdade que muitos professores achavam que a história era uma valiosa fonte de exemplos morais e acreditavam que os alunos deviam aprender a sua história "nacional", eles não necessariamente concordavam sobre o que estes objetivos significavam e muito menos acreditavam que eles eram exaustivos. (A ideia de história "nacional" na Grã-Bretanha e Irlanda do Norte sempre foi repleta de dificuldades, uma vez que o Reino Unido não é, em qualquer sentido, um simples Estado-nação, como é evidente a partir de noções como a da "margem Celta"). A "grande tradição" é ainda menos esclarecedora quando é feita para incluir abordagens de ensino. O estereótipo do professor "ativo" que deposita "os fatos" para o aluno "passivo" é apenas isso, um estereótipo, e ignora a vasta gama de tentativas feitas pelo ensino de história "tradicional" para ajudar os alunos a pensarem sobre a sua história. (Os efeitos nocivos desse tipo de pensamento estereotipado podem ser vistos em recentes declarações que apareceram, até a "interpretação" aparecer no Currículo Nacional em 2000, as questões de interpretação não eram ensinadas na história escolar ${ }^{6}$. Tais alegações são simplesmente erradas ${ }^{7}$.)

A justaposição da história "tradicional" contra a história "progressista", permitida "progressista" para tornar-se simplesmente uma taquigrafia abusiva, era usada para atacar qualquer coisa que parecia ameaçar a exigência de uma história nacional de heróis (geralmente ingleses). Esse tipo de terminologia também ofereceu uma maneira de postular uma idade de ouro, quando todos sabiam a sua história da Inglaterra (raramente da Grã-Bretanha). Além disso, o termo "progressista" foi quase sempre usado para caracterizar algo chamado de "métodos". As mudanças na concepção do que o ensino de história estava tentando conseguir foram descritas como métodos "novos" ou "progressistas", misturando métodos com objetivos e tratando os primeiros como se existissem independentes, práticas autojustificadas com raízes profundas na sabedoria do

6 Isto foi, por um tempo, reivindicado por vários comentaristas. A mais recente ocorrência de que eu tive notícia foi a de um, do Reino Unido (UK), para a Conference em Rotterdam, em 2005, mas não apareceu publicado em debates subsequentes.

7 Eles subsistem erroneamente mesmo se as "Schools History Project and the Cambridge History Project" são ignoradas, embora, anterior a estes projetos, discussões explícitas sobre interpretação têm sido mais comuns para 16 a 18 anos, do que para alunos mais jovens. 
passado. Isto por sua vez levou a um outro par polar de slogans que só poderia parecer útil ou mesmo inteligível se as complexidades de objetivos educacionais fossem ignoradas.

Dois "slogans" desgastados: "Centrada na Criança” versus "Centrada no Conteúdo"

A introdução do "Conselho de Escolas Projeto História 13-16" (mais tarde chamado de "Projeto Escolas de História", ou SHP em inglês) e, especialmente, o seu desenvolvimento, em meados dos anos setenta, produziu "slogans" tolos, como ensino de história "centrado no conteúdo" e "centrado na criança". Pesquisas antes da SHP e o Estudo de Avaliação SHP mais substancial e sofisticado com foco na compreensão de conceitos chave (disciplinares) de segunda ordem nas crianças ${ }^{8}$ permitiram a pessoas dispostas a usar polaridades simplistas assumirem que as mudanças no ensino de história no Reino Unido eram "centradas na criança". No entanto, o propósito de prestar atenção às ideias das crianças foi para habilitá-las a pensar historicamente: não eram apenas quaisquer ideias que estavam em jogo, mas os conceitos centrais para a disciplina. Por isso que a SHP foi considerada, se qualquer sentido pode ser dado a tais "slogans", mais "centrada na criança" do que "centrada no conteúdo". Mas, na realidade, a polaridade era tolice e a tentativa de categorizar as mudanças na educação da história desta forma era ofuscante.

\section{Linguagem não apropriada: "Habilidades" versus "Conteúdos"}

A polaridade de "habilidades" e "conteúdos" é desastrosa de duas maneiras. Primeiro, ela assume que são "habilidades" que estão em jogo na história, e em segundo lugar, ela define o conhecimento do passado como os oferecidos pela história contra a compreensão da natureza das alegações sobre o passado, como se fizesse sentido falar de ensinar um sem o outro. Realmente é hora de abandonar esta "conversa fiada" sobre "habilidades", que é indefensável e prejudicialmente

8 Ver, por ex., Lee (1978); Dickinson e Lee (1978) e Shemilt (1980). Não há uma concordância universal para os conceitos referidos aqui, mas na UK e em outros lugares eles são frequentemente referidos como "segunda ordem", porque eles são conceitos organizadores de alto nível para a disciplina de história. (Há armadilhas linguísticas sempre: falar de riscos da "disciplina" história parece subscrever a ideia de que história é inconteste e seriamente definida. Eu não tenho esta opinião, mas sou inclinado a pensar que, em algum momento, há suficiente argumento para assumir a existência de um núcleo de atividades e algum comum - se claro - objetivo metodológico e explanatório. Naturalmente isto pode mudar com o tempo: comparar as tentativas de caracterizar a história em Walsh (1967) e Megill (2007). 
ainda aparece em grande parte da literatura. A fala sobre "habilidades" permite que as pessoas pensem em termos de habilidades genéricas como "análise" ou "comunicação". Por que devemos usar o tempo das crianças para aprender a análise da história, se isso pode ser feito igualmente bem em qualquer outro assunto? Mas é claro que a análise na história é muito diferente da análise na química (por exemplo), quer nos seus objetivos, nos seus métodos ou em seus critérios de sucesso.

História reivindica atender a padrões intelectuais, exige reflexão, e tem critérios complexos para o "sucesso". História na escola pode ter que atender a critérios adicionais não aplicáveis à história "acadêmica", mas se ela não ensinar aos alunos algo das normas e critérios que são construídos para a história como uma forma pública de conhecimento, não pode ser justificada como história em $\mathrm{si}^{10}$. No ensino de história, como no ensino de qualquer "matéria" que envolve a reorientação cognitiva para o mundo, não estamos preocupados com habilidades de faixa única que podem ser melhoradas simplesmente pela prática e onde, o que conta como sucesso, é incontroverso. Em vez disso, estão tentando desenvolver capacidades de várias faixas complexas que repousam sobre o desenvolvimento de uma nova compreensão conceitual. É claro que tal entendimento permite que os alunos façam novos movimentos intelectuais (históricos) - que é fazer as coisas de forma diferente -, mas se quisermos falar de (por exemplo) "habilidades evidentes" temos de dizer o que "evidentes" significa e o que conta como compreensão evidente na história. A compreensão conceitual é central e sustenta novas habilidades.

Parte do problema pode ser que as pessoas ainda pensam a educação na escola simplesmente como a aprendizagem de conjuntos de informação. Versões mais esclarecidas de tal visão admitem a importância da compreensão, mas não veem isso como sendo relacionado aos conceitos disciplinares específicos. Isso permite que políticos, gestores escolares e até mesmo alguns educadores argumentem que as "disciplinas" escolares são construções arbitrárias e podem ser descartadas com segurança, em troca de estruturas "integradas" que economizam tempo, como humanidades ou estudos sociais. Em nome do desenvolvimento do "bem-estar" e da "autonomia" das crianças o objetivo de expansão cognitiva

9 Devido ao fato de que o hábito é extraordinariamente difundido, seria detestável citar exemplos particulares. Em sua defesa, escritores podem afirmar que está se tornando uma proposta aceita, no que diz respeito a mudanças no pensar acerca da história. Infelizmente, isto é o que a torna tão prejudicial.

10 Gunning (1978, p. 13-14) defende que não era necessária uma conexão entre a história "acadêmica" e a história "escolar". Mas seu argumento parece ser para tornar a história "utilizável" pelos estudantes e ele conclui quase imediatamente que "[...] na maior parte do tempo há uma grande sobreposição entre a história acadêmica e a história utilizada pelos estudantes". 
e a possibilidade de reorientação desaparecem, porque o aparato conceitual diferenciado disponível pelas diferentes disciplinas está escondido (mesmo que não seja abandonado definitivamente). É como se as mais poderosas ferramentas disponíveis para as crianças estejam sendo escondidas ou negadas a elas e a própria base da "autonomia" obscurecida.

O fato de que ambas as "matérias" da escola e "disciplinas" acadêmicas são construções sociais e históricas e não "à prova d'água", filosoficamente, não significa que elas não possuem nenhuma base ou podem ser simplesmente ignoradas. De fato, tal suposição comete precisamente o erro que uma compreensão histórica nos ajuda e nos adverte contra: não podemos fazer o futuro a partir do zero. Além disso, no plano empírico, há evidências de mais de 30 anos de pesquisa sobre a aprendizagem, mostrando que as diferenças entre as disciplinas devem ser levadas a sério. Isto foi resumido pelo projeto norte-americano "Como as pessoas aprendem", que apoia tanto a aprendizagem como o ensino. (BRANSFORD; BROWN; COCKING, 1999). Os conceitos específicos que fornecem uma estrutura de organização de uma disciplina e os tipos de preconcepções que os alunos trazem para diferentes disciplinas, juntos, desempenham um papel essencial de dar substância aos princípios da aprendizagem identificados pelo projeto "Como as pessoas aprendem". (DONOVAN; BRANSFORD; PELLEGRINO, 1999, p. 10-5). Elas também são centrais para o ensino: "Como as pessoas aprendem" deixa claro que o ensino exige uma interação entre o conhecimento disciplinar e o conhecimento pedagógico, onde a compreensão das barreiras conceituais para os estudantes, que "diferem de disciplina para disciplina", é crucial. (BRANSFORD; BROWN; COCKING, 1999, p. 144).

Uma ênfase na interação entre o conhecimento disciplinar e o conhecimento pedagógico diretamente contradiz equívocos comuns sobre o que os professores precisam saber para projetar ambientes efetivos de aprendizagens para seus alunos. Os equívocos são de que o ensino consiste apenas em um conjunto de métodos gerais, que um bom professor pode ensinar qualquer assunto ou que apenas o conhecimento do conteúdo é suficiente. (BRANSFORD; BROWN; COCKING, 1999, p. 144).

A pesquisa também sugere que há diferenças importantes entre a forma como (por exemplo) jovens cientistas naturais e historiadores pensam sobre seus respectivos problemas. (BOIX-MANSILLA, 2001) ${ }^{11}$. E há algumas (mas 
de nenhuma maneira conclusiva) evidências sugerindo que onde a história não é reconhecível no currículo, a progressão sofre ${ }^{12}$.

\section{Compreender a História como uma maneira de ver o mundo}

Se pensarmos em aprender a história como uma forma de reorientação cognitiva, em que as crianças aprendem a ver o mundo de maneiras novas e mais complexas, a realização da aprendizagem histórica torna-se algo que transforma a sua visão e permite possibilidades de ação que tinham sido até então - literalmente - inconcebíveis para elas. A polaridade de "habilidades" e "conteúdos" torna-se irrelevante, pois um dos polos está equivocado. Em vez disso, pode se concentrar nas maneiras em que o desenvolvimento de uma compreensão da história impulsiona o aumento do conhecimento do passado.

\section{O pensamento histórico pode ser contraintuitivo}

Por que pensar em termos de reorientação cognitiva? Pesquisas realizadas durante quase quatro décadas no Reino Unido, e mais recentemente na América do Norte e na Europa, sugerem que a história não é uma atividade de "senso comum", mas, ao contrário, pode ser contraintuitiva ${ }^{13}$. De fato, Sam Wineburg (2001a) chamou a história de um "ato não natural", com base em evidências de pesquisa sobre o "presentismo" de crianças (e adultos). Pesquisas anteriores do Reino Unido sobre a explicação de ações passadas e práticas sociais e sobre a compreensão das crenças e valores do passado (normalmente chamado de "empatia" e, ocasionalmente, "compreensão racional") haviam fornecido evidências consideráveis para a incidência de "presentismo". (DICKINSON; LEE, 1978; ASHBY; LEE, 1987; SHEMILT, 1984). Embora os historiadores acreditem que as pessoas no passado eram tão inteligentes quanto nós, mas tinham ideias diferentes, muitos estudantes, ao contrário, acreditam que as pes-

12 Descobertas não publicadas do Projeto Chata. Parte do estudo envolveu a exploração de conceitos de segunda ordem (disciplinar ou procedimental) em três escolas primárias e seis escolas secundárias durante um ano escolar. A progressão foi fraca em duas escolas (uma primária e uma secundária) onde a história não era claramente demarcada no horário ou na biblioteca e era considerada como um "tópico" metodologicamente tratado ou incluído em um departamento de humanidades.

13 Uma breve discussão desta pesquisa e algumas implicações para o ensino pode ser encontrada em Lee (2005). Para exemplos de pesquisas ver Ashby (2005); Barca (2005); Barton (1996); Boix-Mansilla (2005); Cercadillo (2001); Lee e Ashby (2000); Nakou (2001); Hsiao (2005); Seixas (1993); Wineburg (2001b). 
soas no passado tinham as mesmas crenças e valores que temos, mas eram mais estúpidos (ASHBY; LEE, 1987; LEE; ASHBY, 2001, SHEMILT, 1984) ${ }^{14}$. Se os alunos pensam assim, a história torna-se um catálogo de ações tolas nas quais as alternativas eram claramente disponíveis, mas inexplicavelmente ignoradas. (DICKINSON; LEE, 1978) ${ }^{15}$. É somente quando as crianças abandonam a suposição de que as pessoas no passado viam o mundo como nós, que a história se torna significativamente possível para eles. Portanto, eles devem substituir ideias contraintuitivas por compreensões do senso comum do seu cotidiano.

A pesquisa do Reino Unido sugere que a natureza contraintuitiva do pensamento histórico vai além e estende-se a questões como a possibilidade do conhecimento histórico e à natureza da mudança. Se as crianças assumem que só podemos saber o que podemos testemunhar diretamente e que a história relata um passado fixo (isso só aconteceu uma vez, afinal), então a história é impossível. (LEE; HOWSON, 2009). Histórias da História, ou mesmo declarações factuais singulares, não podem ser levantadas contra o passado para ver se elas podem relatá-lo corretamente, de modo que a história está fadada ao fracasso. Esta visão é talvez relacionada com a maneira pela qual as crianças aprendem a "dizer a verdade". Quando confrontados com perguntas dos pais como "Como é que a janela quebrou?", elas podem dizer o que realmente aconteceu ou elas podem mentir. O passado aconteceu do jeito que aconteceu e elas sabem disso (e de alguma forma os pais muitas vezes parecem saber também). Os critérios do que conta como "a verdade" são compartilhados (ou, pelo menos, fixados por uma autoridade) para que o passado possa parecer ser o critério da verdade. Mas é claro que o que dizemos sobre o passado da história é uma construção com base na evidência - não há passado fixo disponível com um controle sobre o que dizemos sobre ele. E porque os relatos históricos não são cópias do passado, mas compartilham algumas das características de ambas as metáforas e teorias, não pode haver mais de um relato sobre "a mesma coisa", sem um ser necessariamente falso ou distorcido. (LEE; ASHBY, 2000). A mudança na história também pode ser problemática para as crianças, porque elas tendem a assumir que as mudanças são eventos simples. Isso significa que tudo o que acontece é uma mudança e que as mudanças tendem a ser reduzidas em duração e exten-

14 As questões da "empatia" não são limitadas para se entender as ações e práticas sociais humanas; as conexões com os conceitos de evidência histórica precisam ser aprofundadas, porque uma leitura da fonte como evidência depende, em parte, de tomá-la como produzida no interior dos costumes e práticas sociais, ou seja, no contexto em que o vestígio foi produzido. Assim, pode-se perguntar, este vestígio é um objeto da cultura material, por exemplo, um copo ou uma prática ou exortação religiosa?

15 Ver também em Wineburg (2001b, p. 22-24) a discussão das experiências de Primo Levy, destinada a crianças. 
são. Da mesma forma, os processos não intencionais de longo prazo podem ser lidos como escolhas deliberadas feitas em um momento específico no tempo por alguém que quer provocar uma mudança. (BARTON, 1996; SHEMILT, 1983).

Note-se que esta lacuna entre o senso comum no cotidiano e a história ocorre no nível da segunda ordem, os conceitos disciplinares ou estruturais da história. Esses termos são usados para distinguir os conceitos que marcam a forma da atividade dos historiadores em trabalhar dentro da disciplina (por exemplo, a evidência, a mudança, o significado, os relatos) dos conceitos que eles usam em seus relatos substantivos do passado (por exemplo, camponês, empresário, bispo, exército, sexo). Há, é claro, também lacunas entre a compreensão dos historiadores dos conceitos substantivos que empregam e as ideias que os alunos possam ter. Eles não derivam apenas da juventude dos alunos e de seu pensamento imaturo, mas do fato de que o significado de conceitos substantivos muda ao longo do tempo. Um bispo agora não é exatamente o mesmo que um bispo na Idade Média tardia. Mas não há espaço para prosseguir isto aqui e no que se segue será tratado sobre a disjunção entre o cotidiano do senso comum e a história no nível dos conceitos de segunda ordem.

\section{Progressão na compreensão histórica}

Se aceitarmos o caráter contraintuitivo da história, há consequências sobre como construiremos o ensino de história. Torna-se possível perguntar como as crianças se deslocam de suas ideias diárias sobre, por exemplo, se podemos conhecer o passado, para ideias mais poderosas. Podemos usar um termo como "poderoso" aqui porque novas ideias abrem a possibilidade do conhecimento histórico que havia sido fechada pelos antigos (ver Figura 1).

FIGURA 1 - PROGRESSÃO DE IDEIAS QUE FAZEM A HISTÓRIA IMPOSSÍVEL PARA IDEIAS QUE A TORNAM POSSÍVEL

- História é dada em livros = A história é possível

- Nós não estávamos lá por isso não podemos saber = História impossível

- Podemos encontrar testemunhos (pessoas deixaram relatos) = História possível novamente

- Mas eles podem ter sido influenciados ou terem mentido = impossível História

- Podemos usar traços como evidências para fazer perguntas que ninguém pretende nos dizer as respostas $=$ História possível novamente

- Mas, mesmo com a mesma evidência há histórias concorrentes $=$ História impossível

- Relatos são construídos em torno de temas e escalas temporais para responder a diferentes questões $=$ História possível novamente.

FONTE: O autor (2016). 
Muito esforço tem sido dispendido no Reino Unido, tanto por pesquisadores e por examinadores, para produzir modelos válidos e utilizáveis de progressão nas ideias das crianças sobre a história - ou seja, conceitos de segunda ordem ou ideias disciplinares que estruturam a disciplina de história. Pesquisas foram iniciadas em Londres no início dos anos 1970 sobre a compreensão dos adolescentes em explicação da ação e se expandiram para investigar os pressupostos subjacentes às explicações de crianças e adolescentes sobre as práticas sociais. (DICKINSON; LEE, 1978). Muito pouco tempo depois, de forma totalmente independente, um trabalho semelhante começou em Leeds, como parte do desenvolvimento e avaliação do "Conselho de Escolas Projeto História 13-16" Até o início da década de 1980 os pesquisadores de Londres e Leeds tinham tomado conhecimento do trabalho uns dos outros e encontraram um alto grau de concordância nos modelos de progressão que haviam construído.

No início da década de 1980 o trabalho de Leeds ajudou a conduzir grandes mudanças no ensino de história enquanto o SCHP (Conselho de Escolas Projeto História) tornou-se cada vez mais popular nas escolas e a publicação do "Estudo de Avaliação", de Denis Shemilt, em 1980 foi o marco mais importante na pesquisa e desenvolvimento curricular no ensino de história no Reino Unido, na segunda metade do século XX. Enquanto isso, em uma escala menor, a pesquisa de Londres foi expandida para considerar ideias das crianças sobre a evidência e a possibilidade do conhecimento histórico e foram desenvolvidas técnicas para explorar as ideias das crianças em sala de aula, com pesquisa usando gravações de vídeo.

Na época, pesquisas e exames públicos para a SCHP estavam intimamente ligados e novos esquemas posteriores de avaliação estavam sendo desenvolvidos pelos examinadores. Assim, a SCHP forneceu o ímpeto e a oportunidade para o desenvolvimento de técnicas sofisticadas de avaliação, fornecendo também evidências adicionais de larga escala sobre as ideias das crianças e o pensamento histórico ${ }^{17}$.

No final dos anos 1980 um projeto de acompanhamento, a partir do "Conselho de Escolas Projeto História 13-16" (que se tornara simplesmente

16 O time de Leeds usou o termo "empatia” para a área da compreensão da ação e das práticas sociais enquanto que em Londres uma compreensão racional mais pesada foi empregada. Ambos os rótulos poderiam ser facilmente mal interpretados, mas desde que as pesquisas de Leeds eram conectadas à SCHP, elas impactaram diretamente o pensamento dos professores e os pesquisadores de Londres adotaram "empatia" também.

17 Figuras chaves aqui foram Henry Macintosh e John Hamer; ver Macintosh (1983). Hamer articulou a Superintendência e foi, por isto, impossibilitado para publicação, mas o exame dos seus textos e relatórios pelo Southern Examinations Board, no início de 1980, tornou-se exemplar e superou como inovação e guia de ajuda para os professores. 
SHP (Projeto de História Escolar)), foi realizado em Leeds e Londres. Conhecido como o "Projeto de História em Cambridge", desenvolveu um programa para jovens de 16-19 anos de idade, explicitamente com base na progressão da compreensão de conceitos de segunda ordem de evidência, explicações e relatos históricos. Enquanto isso, estava sendo pilotado, pela equipe de Londres, uma pesquisa com base intensiva na escola durante vários anos, iniciando um projeto de pesquisa (Conceitos de História e Abordagens de Ensino ou Chata), explorando as ideias de 320 crianças com idades entre 7 e 14 em evidências históricas, relatos, causa e empatia. Os dados forneceram mais uma prova do desenvolvimento das ideias das crianças e adolescentes que, por sua vez, desempenharam um papel na produção de modelos de progressão mais seguros para conceitos-chave ${ }^{18}$.

A progressão da história, então, pode ser pensada como o desenvolvimento de um aparato conceitual de segunda ordem que permita a história prosseguir, ao invés de forçá-la a uma parada, fazendo mudanças na visão cotidiana da natureza e do estado do conhecimento do passado para um passado histórico. A história é, portanto, uma parte cognitivamente transformadora da educação: ela só é bem-sucedida se permitir às crianças verem o mundo historicamente.

\section{Literacia Histórica: o que significa saber (algo da) História?}

Se o argumento até agora for aceito, o mundo deverá parecer diferente quando pensamos historicamente. Nós não podemos dar um conjunto puro de condições suficientes para serem cumpridas, antes que possamos dizer que alguém "sabe (algo da) história", mas talvez seja permitido tentar uma meta mais modesta de sugerir algumas condições necessárias. Estas devem incluir a compreensão do que uma forma histórica de olhar para o mundo envolve e uma vontade e capacidade de empregar tal entendimento, juntamente com conhecimento substantivo do passado, com a finalidade de orientação no tempo (ver Figura 2) ${ }^{19}$.

18 Porque eles não foram nunca pensados como um modelo terminado ou final, eles nunca foram publicados como uma coleção. Para exemplos de versões correntes de comportamentos com evidência, narrativa histórica e explicação causal, ver Lee e Shemilt (2003, 2004, 2009).

19 A matriz de Jörn Rüsen é sugestiva aqui, em - ao menos implicitamente - relacionar a compreensão da disciplina história com a orientação na vida prática. Ver seu "Paradigmas e reflexão teórica em consciência histórica de jovens da Alemanha Ocidental”, que está incluído em Duvenage (1993). Tudo nesta coleção é merecedor de atenção, mesmo para quem não aceita todos os aspectos de Rüsen sobre a narrativa histórica. Ver em particular "Narrativa histórica: fundamentos, tipos, razões (p. 3-14), "O que é teoria da história?” (p. 15-47), "O desenvolvimento da competência 
FIGURA 2 - CONHECENDO ALGO DA HISTÓRIA

Conhecer algo da história significa:

1. Compreender a história como uma forma de ver o mundo. Isto envolve uma compreensão da disciplina de história, isto é, das ideias-chave que tornam o conhecimento do passado possível, e dos diferentes tipos de reivindicações feitas pela história, incluindo o conhecimento de como podemos inferir e testar afirmações, explicar eventos e processos e fazer relatos do passado.

2. Adquirir disposições que derivam e impulsionam a compreensão histórica, incluindo:

a) A disposição para produzir os melhores argumentos possíveis para quaisquer histórias que contamos relacionadas às nossas perguntas e pressuposições, apelando para a validade das histórias e a verdade de declarações factuais singulares. Adquirir respeito pela evidência é tão importante como a aquisição de um conceito de evidência histórica.

b) Aceitação de que talvez sejamos obrigados a contar histórias diferentes daquelas que preferiríamos dizer (mesmo ao ponto de questionar os nossos próprios pressupostos).

c) O reconhecimento da importância das pessoas do passado, com o mesmo respeito que gostaríamos para nós mesmos como seres humanos.

Juntos, estes elementos implicam que não devemos "saquear" o passado para produzir histórias convenientes para presentes fins.

\section{Desenvolver uma imagem do passado que permita que os alunos se orientem} no tempo.

Trata-se de conhecimento substantivo coerente (às vezes chamado de conteúdo histórico), organizado sob a forma de um passado histórico utilizável, em diferentes escalas. Isso significa ajudar os estudantes a abandonar a visão do presente como algo separado do passado por uma espécie de apartheid temporal, permitindo-lhes, em vez disto, localizarem-se no tempo e verem o passado simultaneamente como repressor e como responsável por possibilidades para o futuro.

FONTE: O autor (2016).

O primeiro grupo de conquistas citadas na Figura 2 já foi discutido aqui na eliminação de alguns dos "slogans" que tendem a atormentar a discussão sobre o

narrativa na aprendizagem histórica: uma hipótese ontológica concernente à consciência moral" (p. 63-84) e "Experiência, interpretação, orientação: três dimensões da aprendizagem histórica" (p. 85-93). Para um simples (e não um simplista) sumário de alguns pontos de vista de Rüsen ver também Lee (2004). Ver ainda Megill (1994) para uma discussão mais profunda. 
ensino de história. Claro, essas conquistas envolvem complicações para além dos três itens listados. Elas não são, por exemplo, questões de "tudo ou nada". Como as crianças podem compreender em maior ou menor grau, é equivocado queixar-se que não se pode esperar que os alunos da escola compreendam a natureza da evidência histórica. A maioria das pessoas pensaria que é um erro tentar descartar o ensino de história na escola porque os adolescentes não conseguem entender totalmente "Carta Magna", o conceito de "providência" ou o Iluminismo. De uma forma um pouco semelhante seria igualmente tolo afirmar que ensinar a ciência escolar é uma perda de tempo, porque a maioria dos historiadores profissionais não entende mecânica quântica. $O$ fato de que a aprendizagem escolar envolve uma compreensão imperfeita - embora talvez em aprimoramento - tanto de assuntos complicados, como de complexas formas de pensar, não é uma razão para abandonar qualquer um destes aspectos da educação.

Também não se deve compreender e subscrever os princípios históricos a serem tomados para implicar que as crianças na escola devam ser capazes de dar explicações filosóficas de evidência ou de mudança na história. Estes são os objetivos históricos, não filosóficos, e eles significam que (por exemplo) quando os alunos encontram relatos do passado fazem perguntas apropriadas e sabem como respondê-las ${ }^{20}$. Esta história explica todas as evidências relevantes? O quão satisfatoriamente ela explica? O que ela não leva em conta? Como ela compara estes termos com relatos concorrentes?

A capacidade de recordar relatos, sem qualquer compreensão dos problemas envolvidos na construção deles ou dos critérios envolvidos na sua avaliação, nada tem de histórico. Sem uma compreensão do que faz um relato ser histórico, não há nada para distinguir a capacidade de recordar os relatos do passado da capacidade de recitar sagas, lendas, mitos ou as obras de JRR Tolkien ${ }^{21}$. Na verdade, para alguns alunos todas serão simplesmente "histórias". O mesmo vale para explicações históricas ${ }^{22}$.

No Reino Unido há certa concordância (até mesmo consagrada no Currículo Nacional) que o primeiro grupo de realizações elencado na Figura 2 é uma

20 A ideia é fornecer aos estudantes habilidades para a compreensão histórica. Mas insisto sobre o fato de que isto não deve minar a importância de uma consciência metacognitiva dos estudantes, nem negar a importância para os professores de um explícito e sofisticado aparato conceitual a ser encontrado na filosofia da história.

21 Sobre ideias dos estudantes acerca das narrativas históricas ver Boix-Mansilla (2005); Lee e Ashby (2000); Gago (2005); Hsiao (2005); Seixas (1993).

22 Sobre ideias dos estudantes acerca da explicação histórica, ver Ashby e Lee (1987); Barca (2005); Dickinson e Lee (1978); Lee, Ashby e Dickinson (1997); Lee, Dickinson e Ashby (1996); Lee e Ashby (2001); Ashby, Dickinson e Lee (2001); Shemilt (1984); Voss, Ciarrochi e Carretero (1998); Voss et al. (1994). 
parte central do aprendizado de algo da história, embora haja pouca ênfase nas disposições do segundo grupo ${ }^{23}$. Quase todos os professores do Reino Unido sublinhariam igualmente a importância de conhecer algo da história substantiva, mas isso pode não ser o mesmo que dizer que eles iriam pertencer ao terceiro grupo de realizações na Figura 2. Tem havido uma tendência de se tratar o passado como um baú cheio de histórias interessantes e até mesmo contos morais, selecionados a partir do que é determinado por uma complexa interação entre o que é exigido pelo Currículo Nacional e entre os próprios instintos e conhecimentos dos professores. Para alguns professores isto tem sido lidado pela sensação de que levar as crianças para trabalhar com evidências ou de pensar em "distância" e desenvolver a empatia, já seria suficiente. Deste ponto de vista, a concentração nos objetivos disciplinares justifica escolhas sem restrições de conteúdos substantivos e apenas critérios pedagógicos ou de preferências pessoais precisariam ser evocados para explicar tais escolhas. Tais ideias podem ainda ser acompanhadas pela invocação da dicotomia "habilidades" versus "conteúdos", apesar do crescente reconhecimento dos seus pontos fracos. Conhecer a história substantiva, então, significa conhecer os itens selecionados, mas nem sempre relacionados da arca do tesouro.

A mesma dicotomia "habilidades versus conteúdo", também é invocada por aqueles que desejam restabelecer uma concepção de história escolar em que "A História" da história britânica é aprendida por todas as crianças. Como a migração e o multiculturalismo crescem em importância política, o mesmo acontece com a demanda para uma coesão social e a história é concebida como um meio central de fortalecimento dos valores nacionais e talvez também de certos tipos de nacionalismo democrático liberal. Por isso, o fornecimento de algo como uma narrativa-mestra da história britânica é novamente uma concepção respeitável de ensino de história entre os políticos e alguns historiadores e professores. É lamentável que alguns historiadores pareçam capazes apenas de defender sua disciplina nestes termos e parecem não ter imaginação para entender o que a história pode fazer para as crianças além disso, ou até mesmo reconhecer que o objetivo de se apoiar em uma única narrativa pode ser a-histórico ${ }^{24}$.

23 Talvez outras pessoas no mundo estejam desenvolvendo e dando ênfases no primeiro grupo. O projeto "Benchmarks" para a reforma da educação no Canadá parece ter seguido uma direção similar e professores e educadores históricos em (por exemplo) Portugal, Brasil e Taiwan têm propostas para seguir em direção a uma concepção mais explícita no que concerne à compreensão da disciplina história.

24 Uma queixa comum em historiadores graduados, tentando um Certificado de Pós-Graduação no curso de Educação, é que seus cursos universitários falharam em provê-los com um aparato para pensar claramente acerca do que está envolvido no fazer a história e parecem não trazer uma concepção de porque a história figuraria na educação, mesmo no nível de graduação. 
As manifestações mais extremas e retóricas desta posição sugerem que os perversos "métodos centrados na criança" minaram a provisão de uma história comum e são a consequência de uma obsessão com as "habilidades"

$\mathrm{Na}$ verdade, é claro, muitos professores do Reino Unido têm estado conscientes há muito tempo que os alunos não estão adquirindo uma visão abrangente do passado a partir da história na escola. Enquanto há claramente um problema, devemos tomar cuidado para não assumirmos que sabemos exatamente qual ele seja. Em particular, deve-se evitar a suposição de que ele é um fracasso de "novos métodos" ou um resultado do relativismo multicultural. Tais hipóteses falham no teste de Sam Wineburg, em que os leitores são convidados a identificar a fonte e a data da seguinte citação: "Certamente uma nota de 33 em 100 sobre os fatos mais simples e óbvios da história dos EUA não é um registro que qualquer escola pode ter orgulho". Wineburg (2000) oferece aos seus leitores relatos e comentários sobre o ensino de história nos EUA, de 1942 a 1987, para serem escolhidos, mas, em seguida, revela que a citação de fato apareceu em 1917 em um artigo do Journal of Educational Psychology relatando um teste com 668 estudantes do ensino médio no Texas. Como ele comenta, “[...] a estabilidade da ignorância dos alunos é intrigante. O mundo inteiro foi virado de cabeça para baixo ao longo dos últimos 80 anos, mas uma coisa, aparentemente, permaneceu a mesma: crianças não conhecem história". (WINEBURG, 2000, p. 307). Apesar de enormes mudanças na sociedade e na vida diária, para não falar em metas educacionais e práticas, a "ignorância" dos alunos da escola parece ter se mantido constante ao longo de quase um século. É possível encontrar exemplos semelhantes na Inglaterra, incluindo este publicado por Engels, em 1845:

Várias [das crianças] nunca tinham ouvido o nome da Rainha nem outros nomes, tais como Nelson, Wellington, Bonaparte, mas era notável que aqueles que nunca tinham ouvido falar nem mesmo de São Paulo, Moisés ou Salomão foram muito bem instruídos quanto à vida, ações e caráter de Dick Turpin, e, especialmente, de Jack Sheppard [o ladrão e fugitivo da prisão $]^{26}$.

25 Ver a Introdução de Davies (1999, p. 25-26), a qual ilustra o algo limitado aparato conceitual trazido por alguns (mas não por todos) historiadores em suas afirmações sobre a educação histórica e faz confusas e infundadas reivindicações sobre a recente educação histórica na UK.

26 Eu devo este exemplo a Arthur Chapman - Quotation from Children's Employment Comission's Report, em Engels (1845). 
Nós não temos nenhuma evidência convincente sobre o quão bem os alunos da escola, e muito menos a população em geral, recordavam "os fatos" de $50 \mathrm{ou}$ 100 anos atrás. Por este motivo, entre outros, também devemos ser cautelosos sobre alegações de que "todo mundo" sabia de uma história comum da história britânica até algum tempo nos anos $1960^{27}$. É discutível que algo como um "modelo de narrativa" do tipo sugerido por Wertsch e Rozin (2004, p. 54) pode ter existido, mas isso não é equivalente a uma narrativa histórica organizando o conhecimento factual. No entanto, há evidências de que os alunos não sabem atualmente algumas das coisas que gostaríamos que eles soubessem, e essa evidência sugere que o déficit, se este é um termo apropriado, não é o resultado de abandonar algo que já sabíamos como fazer, mas agora estamos falhando ao gerenciar. (LEE; HOWSON, 2009). A aquisição que falta é um quadro do passado que permita aos alunos adquirir uma grande imagem do passado em que o presente e novos encontros com o passado possam caber. Este é um problema que está apenas recentemente começando a ser adequadamente formulado e abordado.

Como este quadro deve parecer? Deve ser passível de revisão, porque o que acontece em seguida muda o que podemos legitimamente dizer sobre o passado. (Ninguém podia validamente anunciar em qualquer fase do século XV que eles estavam fazendo parte do início da hegemonia mundial europeia, mas podemos agora querer argumentar que isso era o que estava acontecendo.) Também deve permitir revisões com base em novas compreensões de passagens do passado que os alunos adquirem à medida que envelhecem. Mas, acima de tudo, não pode, se não for para se tornar algo a-histórico, ser "A" história, muito menos algo próximo ao que os russos chamam "história do partido", um relato padrão do passado aprovado pelo estado. Um quadro deve ser uma estrutura aberta de mudança, não uma narrativa em si, mas pode apoiar uma série de narrativas que respondem a diferentes questões e adapte-se a novos pressupostos. Como tal, ele exclui algumas narrativas e faz umas serem um pouco mais defensáveis do que outras. A abertura não significa que "vale-tudo".

Já existe um exemplo muito alardeado de um quadro para a história inglesa: a lista dos reis e rainhas. Tal lista apresenta algumas características genuínas de uma estrutura: não é uma narrativa, nem mesmo uma crônica. Não tem trama, não leva a nada, e ainda ajuda a quem tem de organizar e dar sentido ao passado. No entanto, uma lista de reis é uma estrutura pobre, que mal começa a permitir que o presente seja tratado como o rosto em movimento ao passado. Em contraste, um quadro que identifica mudanças na vida material, organização social e política e uma variedade de outros temas oferece uma ferramenta potencialmente poderosa para permitir uma verdadeira orientação no tempo. Esse quadro de

27 Davies (1999, p. 25-26), faz suposições sobre o que "todas as crianças" sabiam. 
mudança permite aos professores explorar marcadores ou critérios de mudança com os alunos. Quão importante é a "Revolução Neolítica"? Os alunos podem sugerir perguntas para avaliar a mudança, olhando para os estados de coisas antes e depois dela. Qual era o período de tempo necessário para encontrar comida para alimentar uma família? Quais eram os perigos da fome? Que variedade de alimentos estava disponível? Os professores podem incentivar os alunos a considerar quais eram as medidas sociais necessárias antes e depois da Revolução Neolítica e que diferença o excedente fazia. Eles podem fazer perguntas um tanto similares sobre a "Revolução Industrial" e o advento do processamento da informação. E como eles voltariam sempre ao quadro no contexto de estudos aprofundados, poderiam perguntar o quanto estes marcos "são formas úteis de pensar sobre diferentes temas e até que ponto eles são enganosos."

As ideias de segunda ordem estão no coração da compreensão aqui. Distinguir generalizações a partir de declarações factuais singulares e reconhecer a importância central da escala na história são dois exemplos de desenvolvimento conceitual que são prováveis de ser subjacentes ao uso efetivo de quadros estruturais. Se os alunos não entendem que as generalizações podem admitir exceções e que uma generalização que é válida em uma escala pode não ser válida em outra, eles não serão capazes de trabalhar com quadros de estrutura. Ideias de mudança também são importantes. Os alunos que tratam qualquer evento como uma mudança, ou acham que as mudanças têm a mesma lógica de eventos, são susceptíveis de reduzir a escala do passado e vê-lo como a consequência de escolhas deliberadas e ações individuais. (BARTON, 1996). Eles também podem estar inclinados a pensar em qualquer quadro como fixo, algo "descoberto", da mesma forma que os historiadores podem dizer ter descoberto que os vikings chegaram a Labrador.

A progressão em conceitos de segunda ordem ou a compreensão disciplinar é essencial para que a noção do todo seja compreendida como fundamentada e sujeita a critérios e para perceber se os alunos estão caindo ou não na armadilha de imaginar que qualquer história serve. A pesquisa sugere que a maioria dos adolescentes do Reino Unido até 14 anos de idade, pelo menos, é propensa a pensar que os relatos históricos são diferentes porque os historiadores cometem erros ou não são capazes de encontrar as provas, ou, mais comumente, porque os historiadores têm segundas intenções para distorcer suas histórias. No entanto, algumas crianças de 14 anos, talvez mais de 20\%, parecem ter alguma compreensão de que é na natureza de relatos históricos que diferem: eles sabem que as narrativas podem responder a perguntas diferentes e, assim, definir diferentes limites e critérios de relevância. (LEE; ASHBY, 2000) ${ }^{28}$. Portanto, pode 
ser razoável esperar que possamos ensinar os alunos a perguntar se os relatos concorrentes têm o mesmo alcance e poder explicativo, ou são igualmente plausíveis à luz da evidência disponível e do contexto mais amplo do - atualmente - conhecimento aceito.

O ensino eficaz de quadros vai depender de uma imagem melhor de investigação das concepções anteriores dos alunos, os pressupostos ontológicos com que operam, a sua compreensão da mudança e a sua concepção de relatos históricos. Temos provas para algumas dessas ideias, mas pouco da pesquisa foi realizada no contexto de tentar desenvolver quadros e grandes imagens do passado ${ }^{29}$.

Um quadro (concentrando-se em vida material, organização social ou cultura) deve ser ensinado muito rapidamente, talvez, inicialmente, em uma única sessão. (SHEMILT, 2009). É algo a ser desenvolvido ao longo do tempo, como o professor e os alunos retornam a ele em intervalos regulares, melhorando a sua resolução, empregando-o explicitamente para dar sentido a estudos aprofundados e ao mesmo tempo testando-o para ver até onde ele exige qualificação e cautela. Estudos aprofundados podem então se sucederem cronologicamente, se necessário, mas o ponto é que, em vez de esperar que eles de alguma forma estabeleçam uma imagem sedimentar do passado, o ensino é direcionado para a produção de uma estrutura metamórfica, tornada possível através do tratamento do conhecimento obtido a partir de estudos aprofundados assentados no conhecimento do quadro. O objetivo é usar a estrutura de forma contínua, modificando-a e dando aos estudantes o espaço para desenvolver grandes retratos do passado. A natureza não narrativa do quadro permite gerar noções do todo alternativas (narrativas), ancoradas na estrutura e em conhecimento profundo, mas não são fixadas como "história oficial" ou histórias do "partido".

A partir do momento em que as ideias dos estudantes sobre escala, generalização, mudança e narrativas se desenvolvem, eles serão cada vez mais capazes de utilizar os quadros de mudança para produzir noções ampliadas do passado. Em princípio, isto deve permitir-lhes organizar seu conhecimento substantivo de formas historicamente válidas para pensar a relação do presente com o passado e o futuro. Se eles optarem por assim fazê-lo, podem depender de questões fora do controle direto do professor. No entanto, podemos ter certeza de que, se o ensino de história na escola não proporcionar aos alunos os meios para pensar historicamente, não haverá mais ninguém suscetível de fazer isso por nós. Haverá uma abundância de histórias prontas, não necessariamente historicamente defensáveis, para aprender no resto do mundo, mas provavelmente é ingênuo

29 Mas, importantes conquistas têm sido feitas recentemente, por F. Blow, R. Rogers e D. Shemilt. Ver Shemilt (2009). 
e certamente otimista pensar que eles virão com avisos anexados. O ensino de história terá feito o seu trabalho se os alunos tiverem os meios e uma disposição ampla para tentar orientar-se no tempo historicamente. Não pode se prometer sempre que irá competir com sucesso com pressões de identidades culturais, coletivas ou grupais e a pressão que eles trazem para se inscrever em versões menos bem fundamentadas do passado do que poderíamos reivindicar para a história. O sucesso não é garantido ${ }^{30}$.

\section{História transformativa}

Qual o significado do papel da história para os alunos? O que os alunos aprendem a fazer - se nós aprendermos a ensinar história corretamente-que eles não poderiam fazer antes de estudar a história? Como o mundo seria diferente para eles, e se realmente fosse, qual a diferença?

A discussão até agora sugere algumas respostas para estas perguntas. $\mathrm{O}$ desenvolvimento de conceitos de segunda ordem que fornecem a base para a compreensão disciplinar possibilita diversas novas formas de ver o mundo. As mudanças, por exemplo, deixam de ser circunscritas em ações e eventos individuais e incluem também desenvolvimentos extensos e graduais, sendo que algumas não foram intencionadas por ninguém. A aceitação da possibilidade de consequências inesperadas da ação inverte uma imagem simplista de comportamento político e social: boas intenções não garantem resultados felizes e nem tudo o que faz com que haja miséria humana é o produto da maldade. As crenças e os valores das pessoas no passado são entendidos como se não fossem, necessariamente, os mesmos que os nossos, e mesmo que este passado seja estranho, ele ainda é reconhecido como inteligível e defensável em seus próprios termos e, assim, ele pode nos ajudar a dar sentido às crenças e valores atuais. No entanto, transformações desse tipo só podem ocorrer através de e na presença do conhecimento histórico substantivo em que passado e presente não

30 A Comissão De Rooy, na Holanda, tem proposto dar aos estudantes uma periodização do passado, na qual solicitam aos estudantes demonstrarem seus conhecimentos de alguma maneira relevante evitando, assim, a especificação de algum particular e privilegiado item do conhecimento factual. Esta é uma expressiva iniciativa, mas uma periodização "oficial" pode ser um passo em direção a uma história fixa. Ver Wilschut (2009). Nós também necessitamos entender mais sobre como estudantes veem "períodos", que são difíceis de compreender e são caminhos complicados para organizar o passado e podem ser uma base difícil para ensinar história, mais do que se espera. Ver também Halldén (1994, p. 187) para um comentário sobre periodização em Educação Histórica. 
são separados um do outro. O passado não está morto, e, certamente, não se foi. Embora as pessoas muitas vezes falem como se tivessem sido submetidas a alguma forma de parelthontectomy $y^{31}$-, ou seja, um presente separado do que veio antes -, a fronteira fixada entre o passado e o presente é ilusória: muito do nosso pensamento sobre o presente e o futuro, inconscientemente, se refere ao passado ${ }^{32}$.

Se entendermos o que veio acontecendo no passado, então o presente, longe de ser cortado a partir do que o precedeu, junta-se a ele. Por exemplo, as tendências, as tradições e as políticas. Isso não é negar a inversão de tendências, rupturas na tradição ou mudanças políticas, mas reconhecer que falar desta forma só faz sentido se houver algo concebido como uma extensão no tempo para ser invertido, rompido ou para ser modificado. Além disso, nossa ideia sobre o que é ou pode se tornar qualquer nação, partido político ou regime econômico, necessita diretamente do nosso conhecimento do que eles foram no passado. Se quisermos entender os partidos, trabalhista ou conservador na Grã-Bretanha, por exemplo, nós não podemos nos limitar a conhecer seus programas atuais, mas temos que saber como as suas filosofias têm trabalhado na ação prática no passado. Da mesma forma a compreensão do capitalismo significa mais do que citar definições: significa traçar como a vida econômica capitalista se desenvolveu e assim compreender como isto foi possível ou deve ser prevenido. Mesmo nossos conceitos cotidianos necessitam de bagagens temporais: mãe, ferida ou compensação, todos fazem reivindicações sobre ocorrências passadas. (LEE, 1984). Linhas temporais são fundamentais para nossas vidas.

Ninguém vive em um presente instantâneo e a profundidade do passado que evocamos depende, em parte, do que nós estamos pensando. Sabemos que "a arte contemporânea", "a política atual" ou "o pensamento atual sobre o capitalismo" não têm nada a ver com um presente instantâneo. O "presente" parece ser maior ou menor, dependendo do que estamos pensando realmente. De fato algumas questões sobre o presente só podem ser pensadas se tivermos respostas do passado como referências. Por que os americanos, canadenses e australianos falam inglês estando a milhares de quilômetros de distância e os nossos vizinhos mais próximos (mesmo em partes das Ilhas Britânicas) falam línguas comple-

31 Este é um neologismo, mas talvez haja um caso de uma palavra para cobrir a operação de cortar o passado. É como se o estado de espírito, que assume uma desconexão completa entre o passado e o presente, fosse o resultado de um procedimento em que o passado foi radicalmente extirpado. (A responsabilidade por sobrecarregar o discurso com uma criação desajeitada é inteiramente minha, mas eu devo qualquer sentido feito pelo grego para Irene Nakou.)

32 A questão aqui, naturalmente, não é que o passado pode ou poderia dar alguma direção simples, mas nós construímos o mundo como sendo no tempo e as limítrofes e fronteiriças noções temporais, como orientação, tradição e sentidos políticos manifestam isto. 
tamente diferentes? Por que nós realisticamente temos que escolher entre dois ou três partidos políticos para formar um governo $?^{33}$ Respostas inteligíveis para estas perguntas devem refletir (mesmo sem esgotá-las) a contingência histórica.

A afirmação de que a história é transformativa, então, deve recorrer ao conhecimento histórico disciplinar e substantivo e negar a separação que divide o passado do presente. Não há espaço aqui para desenvolver esta afirmação completamente, mas podemos oferecer um esboço de alguns componentes que podem ser utilizados em uma discussão adequada. Mas, primeiro, talvez devêssemos perguntar por que existe a necessidade de falar deste percurso.

É importante salientar a natureza transformativa da história porque, sem qualquer questionamento de que a história modifica nossa visão sobre o presente e o futuro, o conhecimento do passado é considerado como sendo o acúmulo de fatos ou histórias que estão necessariamente confinados a esse passado e, portanto, são irrelevantes para qualquer situação no presente. Nestas circunstâncias, a maioria da promoção atual da história na educação recai sobre as reivindicações instrumentais de curto prazo, discutidas anteriormente: a história atualmente pode fazer tudo o que os políticos acreditam ser essencial para a economia ou a coerência do Estado-nação. Este é o tipo de justificativa sobre o lugar da história no currículo - ela pode "promover" a cidadania, numeracia, literacia ou qualquer coisa exigida - que incentiva os diretores e políticos a acreditarem que os argumentos para a história são fracos. Quando tais justificativas são combinadas com as ditas "habilidades", a história torna-se apenas uma das muitas formas de produzir os resultados genéricos desejados e perde sua força na luta por espaço em um currículo lotado. Isto também nos impede de ver claramente sobre o que deve ser incluído em um currículo de história e os objetivos tornam-se confusos ou simplesmente entregues pelos governos.

Por que a história transformativa é um caso tão raro de ocorrência? Uma resposta a esta pergunta é que qualquer caso deve ser cauteloso, qualificado e estar bem consolidado e não pautar-se em afirmações gerais, pois, a fim de especificar que tipo de transformação pode ser feita, temos que saber tanto quais são as ideias iniciais das pessoas como quais perguntas estão em jogo. As concepções iniciais das pessoas sobre o passado humano são imensamente diferentes em caráter e escopo e seu interesse no passado (em ambos os sentidos de "interesse") pode ser igualmente diverso. Tais concepções iniciais são ainda mais importantes quando estamos preocupados com a educação, principalmente com crianças e adolescentes. A transformação do mundo para o aluno pode ser radical, porque é pouco provável que o conhecimento e o entendimento inicial

33 Ver Borries (2009) para exemplificar questões deste tipo. 
deles estejam ricos ou profundos. (Claro que pode ocorrer, mas isso é incomum e provavelmente tenha um caráter precário $)^{34}$.

Diferentes ideias e interesses iniciais significam que as consequências de mudar a forma como as pessoas veem qualquer evento particular ou passagem do passado tendem a diferir consideravelmente. É difícil dar exemplos concretos, a menos que possamos definir as concepções iniciais em um caso específico ${ }^{35}$. No entanto, a história é transformativa. É quase um lugar-comum no qual os governos negociam sobre este assunto ${ }^{36}$. Assume-se que os alunos possuem pouco conhecimento do passado (poucas concepções iniciais) e os políticos e outros, que desejam moldar a visão dos alunos, de presente e futuro, e tentam transmitir uma versão apropriada do passado - uma que faça os alunos mais patrióticos ou mais religiosos, ou melhores comunistas ou democratas liberais, ou mais fieis a uma dinastia ou partido. Se os esforços dos governos serão suscetíveis de sucesso ou falha depende (entre outras coisas) sobre como se organizam as ideias iniciais dos alunos sobre o passado e pesquisas sugerem que a suposição de que tais ideias são inexistentes é perigosa. (EPSTEIN, 2001; WERTSCH; ROZIN, 1998). No entanto, mesmo que as abordagens adotadas sejam simplistas e equivocadas, os governos não estão errados em reconhecer que a história pode mudar a forma como as pessoas veem o seu mundo.

Deve ficar claro, a partir do que já foi dito, que este não é um argumento para a apologia a abordagens sobre o passado que tratam a Educação Histórica como uma forma de engenharia social que irá saquear o passado para atender preferências presentes. $\mathrm{O}$ argumento que se segue visa, precisamente, substituir uma visão transformacional, desvelando alguns elementos da transformação que o conhecimento histórico e a compreensão podem produzir. Talvez uma digressão, utilizando uma analogia, poderia ser útil aqui.

34 Como sempre, em situações deste tipo, cautela é necessária. Há evidências, por exemplo, que somente os jovens de 14 anos têm ideias mais sofisticadas sobre narrativas históricas, mais do que aqueles que parecem estar sujeitos a mais comentários e opiniões sobre o passado, onde a presença de histórias conflituosas é vista como um sinal de uma partida a partir de uma história fixa e terminada, ou como uma indicação de constituição de opiniões servindo a outros motivos. Mas aqui nós estamos lidando com possíveis transformações de concepções de segunda ordem.

35 Se existem evidências de pesquisas adequadas acerca de grupos de concepções substantivas realizadas em geral por grupos, nós podemos ser capazes de fazer afirmações relativas aos níveis de grupos sobre os resultados prováveis de transformação do conhecimento histórico, mas nós estamos longe de ser capazes de fazer isto no presente. As possibilidades transformativas de segunda ordem ou do conhecimento disciplinar estão mais ou menos bem documentadas, como nas primeiras discussões realizadas neste texto talvez indiquem.

36 Há uma vasta literatura sobre políticas - no sentido amplo - de manuais de história e currículo. Para exemplos recentes ao redor do mundo, ver Foster e Crawford (2006). Para exemplo de uma discussão mais localizada, ver Koulouri (2002). 
No Reino Unido, quando um guarda de caça ou um amante de pássaros percebem uma gralha, eles são capazes de fazer um som de desaprovação: "Eles são pássaros horríveis" "Eles atacam as aves que cantam", "Eu prefiro vê-los mortos e pendurados em um fio em linhas" e assim por diante ${ }^{37}$. Do ponto de vista de um guarda de caça, cuja função é preservar aves de caça para a sua destruição por outros meios (homens com armas), ou de um amante de pássaros, que tem prazer em ver e ouvir o canto dos pássaros, estes são comentários perfeitamente razoáveis. Eles organizam o mundo natural de acordo com suas necessidades presentes. Um cientista, no entanto, é provável que considere a gralha simplesmente como outra espécie de pássaro com o seu próprio nicho ambiental. Eles fazem parte de uma ecologia mais ampla e não algo para ser julgado a partir de desejos humanos. A ciência tenta se afastar de nossos desejos imediatos e faz perguntas que muitas vezes não podem sequer ser colocadas na linguagem de situações diárias. Compreender as gralhas envolve estabelecê-las em muitas outras "histórias", além daquela em que eles podem ou não causar "danos" a outras espécies. E, curiosamente, as nossas chances de perseguir objetivos práticos imediatos, muitas vezes podem melhorar se nos afastarmos deles. (A política contestada de erradicar texugos em uma tentativa de evitar a tuberculose bovina aumenta esta possibilidade.)

Esta é uma viável, mas incompleta, analogia em relação à nossa posição ao passado. Nosso instinto todos os dias é o de organizar o passado de maneira que reflita nossos desejos e preferências imediatas. Louvamos e condenamos o que encontramos lá e tiramos lições com base em nossa aprovação ou desalento. Mas a história (entendida como uma forma pública de construção do conhecimento) aspira a uma espécie de ecologia temporal. Houve tentativas de evitar a visão do mundo inteiramente em termos de nossos interesses práticos e desejos, na tentativa de ver o passado humano em toda a sua inter-relação complexa. Isso significa entender o que nos interessa (por qualquer motivo), no contexto de muitas histórias diferentes, assim como com as gralhas ou texugos ${ }^{38}$. Claro que os historiadores podem, a qualquer momento, adotar a postura do guarda de caça ou a postura dos amantes de pássaros, e organizar o passado para eleger ações desejáveis ou indesejáveis, eventos ou processos. Mas a história, como uma tradição cognitiva pública e reflexiva, reconhece que o passado toma a forma que desejamos lhe dar, e que, se de fato quisermos recomendá-la para o uso prático diário, é melhor certificar-se de que primeiro entendemos seu

37 Gralhas são espécies comuns na UK, mas talvez menos observadas.

38 Carências no entendimento disto provocam fortes enganos como a tentativa de classificar eventos como historicamente significativos, independentemente das histórias ou escalas de tempo. Significância histórica não é uma propriedade fixa dos eventos, mesmo que algum grau de concordância sobre o que é humanamente importante possa nos confundir em pensar desta maneira. 
funcionamento como uma ecologia temporal. Nada pode ser menos enganoso, talvez de forma análoga à forma como a postura do fazendeiro que levou ao desastre no qual coelhos comiam todo o Porto Santo no início do século XV. (CROSBY, 1986, p. 75).

O que um tipo de história de transformação pode fazer (e que muitas vezes é visivelmente distante dos programas de história do governo) é incentivar um grau de cautela, nos tornando conscientes do que não dizer. A história pode transformar as simplicidades de um mundo categorizadas em polaridades ou organizadas em generalizações, muitos das quais têm a sua origem em "memórias" do passado, mas não em história. Afirmações precipitadas como "apaziguamento agora levam a guerras mais tarde" optam por fazer, de forma relevante, o passado e o presente semelhantes e o conhecimento histórico (bem como evidências quanto ao que pode ser afirmado sobre o presente) deve ter sua validade testada em todos os casos. Analogias entre migração e suas consequências no Império Romano do Ocidente e migração em alguns países da União Europeia, por exemplo, ou entre a crise financeira de 2007 e recessões anteriores ou a Grande Depressão, pedir explicitamente questões sobre o passado, bem como o presente, exige considerável conhecimento histórico. Sem esse conhecimento, as analogias são suscetíveis de ser incompreensíveis ou perigosamente enganosos; com isso, eles podem nos permitir ver o nosso mundo presente de maneiras novas e menos simplistas. Atenção e percepção de incertezas, apesar de serem conquistas notáveis, não são suficientes e podem ser inclusive paralisantes. Jerry, de 17 anos, que não estudava história desde que tinha 14 anos, foi questionado no início de 2002 sobre qual tipo de evento seria 9/11, e ele respondeu: "Estamos de joelhos no desconhecido"39. Uma história transformativa deve ter mais ambições positivas.

A maneira pela qual a história transforma a forma como vemos o mundo pode ser dramática. O conhecimento do passado clássico, adquirido durante o Renascimento, mudou as ideias dos europeus sobre o que e quem eles eram e suas perspectivas sobre as possibilidades do futuro. O desenvolvimento do conhecimento sobre o "tempo profundo", no final do século XVIII e início do século XIX, alterou radicalmente as ideias das pessoas sobre o tipo de mundo que os seres humanos e animais estavam vivendo. E, portanto, eventualmente, alterou, inclusive, algumas concepções sobre a própria humanidade. Mais uma vez, a transformação da forma como as pessoas atribuem sentido ao seu mundo, nestes exemplos, dependia de suas ideias anteriores e da força da resistência de algumas pessoas para a nova história da Terra e da vida em si, esta é uma indicação de quão profundas tais mudanças poderiam ser. (TOULMIN; GOODFIELD, 1965).

39 Estudo piloto sobre consciência histórica, 2002. Ver Lee (2004). 
Da mesma forma, as transformações provocadas pela história podem ser muito mais simples de alcançar e talvez mais imediatas em suas implicações. Por exemplo, alguns alunos de uma turma de 15 anos de idade, envolvidos em "Estudo de Desenvolvimento" da medicina, considerando a importância de Pasteur, foram introduzidos, a partir de Kuhn (1992), nas ideias sobre paradigmas científicos, revoluções e resolução de problemas ${ }^{40}$. Muitos dos alunos estavam estudando, principalmente, as disciplinas de ciências para os seus exames e eles se aproximaram dos professores no final da aula com considerável emoção, porque sempre entenderam que a ciência natural era uma estrutura construída de conhecimento em grande parte imutável e que suas vidas como futuros cientistas, na melhor das hipóteses, consistiriam em fazer pequenas adições ao edifício. Sua concepção de ciência tinha sido derrubada: De repente, perceberam, como um deles disse, que "Nós podemos até ser capazes de fazer uma grande diferença". Esta foi uma transformação radical, embora o tema ainda exigisse uma compreensão mais complexa e profunda.

Mesmo ao nível individual e em escala bem detalhada, a história da ação política pode mudar a forma como os alunos veem o seu mundo. Os alunos que conhecem Winston Churchill como um líder de guerra heroico e bem-sucedido podem ter dificuldades para entender por que ele foi rejeitado pelo eleitorado britânico em 1945, mas a partir do entendimento de que suas aspirações políticas e sociais naquele período foram contextualizadas nas décadas anteriores, sua concepção, tanto de política quanto de sociedade muda e, com ela (para alguns alunos), é adquirida uma compreensão mais sutil dos tipos de possibilidades e restrições para a ação política e social no presente e futuro.

A história, então, pode transformar a forma como vemos as coisas em escalas e maneiras muito diferentes. Ela pode derrubar explicações ou sugerir outras melhores, como no livro de Jared Diamond (1997) Armas, Germes e $A c ̧ o$, que mostra como as declarações de hegemonia europeia em termos de superioridade cultural e muito menos racial são inadequadas. Mudanças nas explicações podem - como neste caso - ter implicações para o entendimento de nossa identidade e até mesmo para o julgamento das feridas que carregamos do passado, bem como, em geral, para as nossas ideias de como as coisas acontecem. Estudantes negros que assumem (infelizmente porque professores bem-intencionados reforçam tais crenças) que apenas os negros foram feitos escravos, podem mudar todo sentido de quem eles são quando entendem que

40 A lição em questão é parte de um programa de pesquisa em sala de aula promovido e desenvolvido no Projeto Chata, realizado numa escola de Essex. Observe que, a despeito de algumas curiosas propostas para reescrever a história na literatura profissional recente, a "significância" foi ativamente adotada por professores historiadores muito antes de seu aparecimento no currículo oficial. 
a escravidão era uma característica normal das sociedades de baixa energia e que europeus e asiáticos também foram escravizados em grande número ${ }^{41}$. Da mesma forma, os estudantes brancos que imaginam que os problemas dos países africanos são de alguma forma inteiramente autoinfligidos podem ver o mundo de forma muito diferente, ao considerar as evidências de que a escravidão desempenhou um papel importante na criação e manutenção desses problemas. (NUNN, 2010). O conhecimento histórico sobre o passado pode também mudar a identidade de forma muito mais simples. Os produtores de um canal de televisão (Channel Four TV) em um recente relato da batalha de Trafalgar estavam claramente cientes disso quando enfatizaram o papel de "estrangeiros" na batalha e na Marinha Real do século XVIII e início do século XIX, pensando claramente que a noção de "britanismo" seria expandida ${ }^{42}$.

Mudanças na forma como vemos o mundo podem provocar revisões radicais de nossas suposições a respeito de quem somos e de como o mundo funciona. Um exemplo de grande escala é o tratado feito por McNeills' (2003) sobre o crescimento dos tributos tomando as sociedades - aristocracias militares ou elites (e religiões obsoletas) - como formas de parasitismo. Um exemplo de uma revisão em escala tipicamente histórica pode ser a insistência de N. A. M. Rodger (1997 e 2004) que a Marinha Real não pode simplesmente ser entendida como uma máquina de combate ou até mesmo um baluarte defensivo ou um meio de expansão colonial e imperial, mas como uma pioneira da logística de grande porte e motor econômico em si mesmo, uma instituição de natureza até então não correspondida na Europa. Além disso, as transformações podem ser mais específicas do que o simples abandono de suposições implícitas ou tácitas e mais próximas de uma mudança de perspectiva. Nossa concepção dos Estados Unidos altera se pensarmos a Revolução Americana não apenas como uma busca pela liberdade, mas como uma oportunidade para as elites locais ampliarem seu poder político e econômico.

As transformações provocadas pelo conhecimento histórico são muitas vezes complexas e matizadas, porque elas frequentemente envolvem relações recíprocas entre o passado e o presente. Nossas ideias atuais sobre o que os seres humanos são podem informar nosso ponto de vista, por exemplo, a ideia de progresso do século XIX ou o nazismo e o Holocausto, ou ainda o desenvolvimento do Estado de Bem-Estar no Reino Unido depois de 1945, e nossa compreensão destas contrariedades modifica e enriquece nossa compreensão de quem somos

41 Traille (2006) fornece evidências empíricas dos efeitos de certos tipos de ensino e dos preconceitos que eles produzem. Isto significa que não é para suprimir as importantes diferenças entre a escravidão Atlântica e outros tipos de escravidão.

42 Canal 4, programa de televisão em UK - 28/10/2010. 
e podemos ser. Mais uma vez, isso aponta para a importância, para qualquer consideração, sobre o poder transformativo da história em nossas concepções iniciais. Se diferentes pessoas têm diferentes noções sobre o comportamento dos seres humanos como indivíduos ou em sociedades organizadas, o impacto sobre eles promovido pelo novo conhecimento histórico será diferente. Isto se aplica às memórias também, se recordações atuais de acontecimentos ou estados de coisas ou lembranças das crenças comuns sobre a passagem do passado, em sentido desconexo, às vezes são chamadas "memória"

Por exemplo, as memórias da geração do meu pai sobre o papel da Alemanha na Segunda Guerra Mundial configuram a forma como Alemanha era vista, isto é, as ideias sobre o que os alemães eram ou do que eram capazes; as expectativas que deveriam ter dos alemães para o futuro; ou mesmo quanto ao grau de confiança apropriado aos alemães. Tudo isso teve consequências importantes para a política externa. Mas houve diferenças relevantes dentro da mesma geração, dependendo de quanto da história as pessoas sabiam e qual era essa história. Aqueles, por exemplo, que estavam conscientes do impacto científico, filosófico e cultural da Alemanha antes dos nazistas viram um país muito diferente das pessoas que simplesmente tinham memórias muitas vezes da guerra e suas origens imediatas.

Diferenças semelhantes podem ser vistas na forma como a Europa e a União Europeia são concebidas por aqueles com e sem conhecimento da história da música, literatura e cultura europeia. Se, por exemplo, o passado da União Europeia é concebido como apenas uma questão de mudanças no balanço financeiro que produzem perdas ou ganhos para o Reino Unido, então muito do que é feito no presente e no futuro será incompreensível. Hipóteses sobre a identidade e entendimento das tradições e políticas, tudo estará comprometido. Alguns compreendem a história europeia e o surgimento da União Europeia, após a Segunda Guerra Mundial, como o processo de transformação de uma instituição burocrática ininteligível sem propósito em uma representação complexa de medos e esperanças decorrentes da experiência da Europa ao longo de décadas, se não séculos. Ganhos e perdas financeiras para os países membros tomaram o seu lugar em um conjunto de funções e objetivos mais amplos e

43 O que nós acreditamos como verdade - sobre o passado - fora de nossa própria experiência ou escala temporal não é memória, mas se consideramos seu impacto sobre a imagem do mundo com a qual trabalhamos pode muito bem ser. Mesmo assim, pode haver razões para a não anulação das reivindicações de memórias individuais em relação às da "memória" no sentido mais amplo. Se aparecer como falso, deixará de ser memória, considerando que aqueles que usam o termo neste último sentido sejam inclinados a ser menos rigorosos. No caso de memórias sociais no sentido amplo, relativismo pode ser defensável, em situações em que isto não se refere à memória em um sentido mais apertado. 
assim a União Europeia (como as gralhas) podem começar a se encaixar em muitas histórias possíveis ${ }^{44}$.

O campo das ideias que a história é capaz de transformar pode se estender para além de qualquer conteúdo específico, para concepções muito mais generalizadas que fundamentam a nossa maneira de conceber o mundo. Especialmente em relação às concepções das crianças e adolescentes. Sem o conhecimento histórico, as ideias das pessoas sobre o que é normal nas questões da humanidade tendem a ser limitadas ao aqui e ao agora. Em algumas áreas da vida humana (religião ou lei, por exemplo) as ideias dos adultos sobre o que é o normal alegam retornar ao passado distante, mas frequentemente esta normalidade é apenas a maneira de fazer algo no presente ${ }^{45}$.

As consequências de uma noção de normalidade localizada podem aparecer em formas inesperadas. Considere, por exemplo, o impacto da internet e das novas tecnologias sobre os hábitos de leitura. Debates sobre isso muitas vezes tomam forma a partir das preocupações sobre a perda das capacidades ou competências, entendida como a representação de uma interrupção das atividades "normais" dos jovens. Estas preocupações não desaparecem com o conhecimento histórico, mas, uma vez que a normalidade é considerada em um contexto histórico, toda a coisa muda de figura. Mesmo se deixarmos de lado o fato que durante longos períodos do passado poucas pessoas sabiam ler, o conhecimento histórico define as questões sob uma luz diferente. A invenção da escrita, por exemplo, levou à perda ou degradação de importantes realizações humanas e habilidades na memorização de mitos de origem e narrativas épicas, essenciais para a transmissão da cultura. Se a nova tecnologia está matando a alfabetização, em primeiro lugar as tecnologias de escrita mataram a memória oral.

Para os alunos na escola, a visão de que o presente é normal tende a ser ainda mais pronunciada. Quando os estudantes assumem o seu mundo presente como definidor do que é normal para a vida humana, não é de surpreender que eles esperem poucas mudanças em suas vidas futuras. A mudança tecnológica tem grande influência em seu pensamento, mas para alguns alunos ela pode mesmo estar chegando ao fim ou pelo menos estar perdendo o seu impacto sobre a vida "comum". Para os alunos de 16 e 17 anos de idade seguintes, por exemplo, todas as grandes invenções já foram feitas.

44 Isto não é dizer que a justa distribuição financeira ou burocracia são assuntos sem importância, mas para reconhecer a fim de lidar eficazmente com eles, que devem ser definidos em uma variedade de oportunidades e restrições para a ação indicada por uma compreensão do passado.

45 Religiosas e jurídicas abordagens ao passado são muitas vezes (embora talvez não sempre) formas de tentar organizar o passado para servir convenientemente aos presentes desejos práticos ou esperanças. 
Lynne: Eu não acho que nós vamos ter como grandes mudanças em termos tecnológicos, como nos últimos quarenta anos. Porque é assim, eles estão sempre fazendo avanços sobre as coisas, mas eles nunca estão inventando nada de realmente novo, como a televisão e tal. Não havia nada antes disso, ou os telefones, não havia nada antes disso.

Sasha: E essas invenções são apenas formas de desenvolvimento.

Entrevistador: Então você está dizendo que essas alterações não podem ser tão grandes quanto as do passado?

Lynne: Vão ser como melhorias em coisas que já estão aqui. ${ }^{46}$

Há paradoxos interessantes aqui ${ }^{47}$. As ideias de que o presente define o que é normal (o que significa dizer que, em geral, as mudanças serão marginais e a vida vai continuar como sempre foi) aparecem muitas vezes acompanhadas da conviç̧ão de que o passado não tem qualquer relação com o presente, porque tudo muda: a mudança torna a história inútil. Danny, de 14 anos, frequenta uma escola no sudeste da Inglaterra e quando perguntado se a história pode ajudar a decidir como lidar com problemas nas relações raciais respondeu: "Não, porque, como eu já disse, os tempos mudam e as pessoas mudam". Ele respondeu quase da mesma forma às perguntas sobre as decisões políticas e econômicas. Kate, de 15 anos, estudante de uma escola da região de Londres declarou: " $A$ história é realmente inútil, porque se as coisas mudam com o passar do tempo então não há realmente nenhuma necessidade de aprender sobre o passado"48.

De modo geral, é difícil para os alunos das escolas entenderem que o estado atual de alguns assuntos (econômicos, sociais ou políticos) no mundo é temporário e representam um ponto em um processo contínuo de mudança. A ideia de que existiu um mundo onde havia pessoas vivendo normalmente da caça e da coleta é estranho para eles e isso faz com que seja difícil compreender a complexidade das mudanças que permitiram a geração de excedentes econômicos e

46 Entrevista em um estudo piloto em pequena escala da consciência histórica, realizado pelo autor, em 2002, em uma escola abrangente de Essex. Lynne tinha estudado a história aos 16 anos de idade, Sasha aos 14 anos. Ver Lee (2004).

47 Exemplo de escrita de dados coletados no estudo piloto da consciência histórica, 2002. Este rapaz frequenta uma escola de gramática em SE, Inglaterra. Ele repetiu esta forma de palavras três vezes em resposta às perguntas diferentes sobre se a história pode ajudar a decidir como lidar com problemas na política, economia ou relações raciais. Mais da metade das 60 respostas (todas de rapazes no $7^{\circ}$ e $9^{\circ}$ anos) tomaram uma posição semelhante.

48 Exemplo do Usable Historical Pastproject, 2006-8, financiado pelo ESRC (Conselho de Pesquisas e Estudos sobre Raça). 
com ela a possibilidade de culturas urbanas. A possibilidade de que as mudanças futuras podem não seguir a trajetória a que estamos acostumados, ainda mais, que a direção pode reverter é ainda mais difícil para os alunos compreenderem.

Por isso, sempre que considerarem tais mudanças em tudo, existem algumas evidências que isso possa ocorrer no contexto de súbitas catástrofes naturais ou possivelmente com guerras, ao contrário de, por exemplo, uma consequência mais gradual do esgotamento dos recursos ou aumento da demanda ou então de mudanças nas crenças e valores ${ }^{49}$.

Quando o conhecimento histórico começa a minar as suposições sobre normalidade, ele incentiva mais nuâncias nas expectativas sobre o futuro. Geoff, por exemplo, um estudante de nível A, respondendo a outro estudante que afirmou que, de forma geral, é provável que a vida fique igual nos próximos 40 anos, chamou a atenção para as expectativas distorcidas de mudança criadas na década de 1950.

É muito difícil descobrir como serão as mudanças revolucionárias sendo que você pode afirmar que irá ocorrer uma evolução na tecnologia. Se você olhar, por exemplo, a visão da década de 1950 de como seria o ano de 2000, você tinha todas essas imagens iluminadas, casas futuristas, mas ainda com a mulher em casa fazendo a comida, com a ajuda de todos estes dispositivos fantásticos. Eles nunca anteciparam as mudanças sociais que mudariam o papel das mulheres na sociedade ${ }^{50}$.

\section{Conclusão}

A história tem um lugar na educação porque desenvolve a consciência histórica dos alunos, localizando-os no mundo, de forma a incentivá-los a pensar sobre as relações temporais ${ }^{51}$. Essas relações, de uma maneira ou de outra, com

49 A evidência é, no mínimo, sugestiva: é necessário um esforço muito maior nesta área. Em grande escala, há algumas evidências do Youth and History Project sugerindo que alunos de inglês e galês esperam que futuras mudanças podem ser mais o resultado do material e impessoal das forças do que realmente o que acontecia no passado; Ver Lee et al. (1997). Em pequena escala, no estudo piloto de 2002 da consciência histórica, dados de entrevista de um pequeno grupo de estudantes de duas escolas de Essex sugerem as expectativas que se alguma coisa pode produzir grande alteração no que é concebido como "normal" na vida no presente serão os desastres ecológicos ou guerras.

50 Resposta do estudo piloto da consciência histórica, 2002. Alguns dos alunos da amostra responderam com tal sofisticação.

51 Rüsen faz um relato esclarecedor da consciência histórica e constrói o espaço nela para a história como uma forma de conhecimento. Mas a consciência histórica é mais larga do que o 
ou sem consciência dos alunos, criam restrições e oportunidades (estabelecem o contexto) em que seus pensamentos e ações podem operar no presente e futuro. E a história faz isso de uma maneira particular, um modo que, para a maioria dos estudantes, é improvável que seja oferecido a eles fora da escola ou fora do contexto da educação formal. Se os nossos alunos aprendem a abordar o passado historicamente, eles terão disponível a possibilidade, não só de se apegar ou abandonar suas lealdades, tradições e fidelidades sociais ou políticas, mas de vê-las sob uma luz diferente. A Educação Histórica não deve apenas confirmar formas de pensar que os alunos já têm: ela deve desenvolver e expandir seu aparato conceitual, ajudar os alunos a verem a importância das formas de argumentação e conhecimento e assim permitir que decidam sobre a importância das disposições que fazem essas normas atuantes. Ela deve desenvolver um determinado tipo de consciência histórica - uma forma de literacia histórica - tornando possível ao aluno experimentar diferentes maneiras de abordar o passado (incluindo a história) incluindo a si mesmo como objeto de investigação histórica. A história pode ser entendida, como outras formas públicas de conhecimento, como uma tradição metacognitiva, na qual pessoas têm lutado há tempos para torná-la uma prática possível. Como a ciência natural ou social é uma conquista precária. Ela deve ser tratada com respeito e cuidado nas escolas.

\section{REFERÊNCIAS}

ASHBY, R. Students'Approaches to Validating Historical Claims. In: ASHBY, R.; GORDON, P.; LEE, P. J. (Ed.). Understanding History - Recent Research in History Education: v. 4. International Review of History Education. London: Woburn Press, 2005. p. 21-36.

ASHBY, R.; LEE, P. J. Children's concepts of empathy and understanding in history. In: PORTAL, C. (Ed.). The History Curriculum for Teachers. Lewes: Falmer Press, 1987. p. 62-88.

ASHBY, R.; DICKINSON, A.; LEE, P. Projeto Chata: concepts of History and Teaching Approaches at key stages 2 and 3. Teaching History, v. 82, p. 6-30, 2001.

BARCA, I. 'Till New Facts are Discovered': Students' Ideas about Objectivity in History. In: ASHBY, R.; GORDON, P.; LEE, P. J. (Ed.). Understanding History - Recent Research in History Education: v. 4. International Review of History Education London: Woburn Press, 2005. p. 68-82

tipo de literacia histórica que deve ser oferecido por um ensino de história e nem todas as formas de consciência histórica cumprem as normas da história. 
BARTON, K. Narrative simplifications in elementary students' historical thinking. In: BROPHY, J. (Ed.). Advances in Research on Teaching: Teaching and Learning History. Greenwich: JAI Press, 1996. p. 51-83.

BOIX-MANSILLA, V. The Pursuit of Understanding: A Study of Exemplary High School Students' Conceptions of Knowledge Validation in Science and History. Unpublished PhD thesis, Harvard Graduate School of Education, 2001.

BOIX-MANSILLA, V. Between reproducing and organizing the past: students' beliefs about the standards of acceptability of historical knowledge. In: ASHBY, R.; GORDON, P.; LEE, P. J. (Ed.). Understanding History - Recent Research in History Education: v. 4. International Review of History Education. London: RoutledgeFalmer, 2005. p. 98-115.

BORRIES, B. von. Competence of historical thinking, mastering of a historical framework, or knowledge of the canon? In: SYMCOX, L.; WILSCHUT, A. (Ed.). National history standards - The problem of the canon and the future of teaching history: v. 5 . International Review of History Education series. Charlotte: Information Age Publishing, 2009. p. 283-306.

BRANSFORD, J. D.; BROWN, A. L.; COCKING, R. R. (Ed.). How People Learn: Brain, Mind, Experience and School. Washington DC: National Academy Press, 1999.

CERCADILLO, L. Significance in History: Students' Ideas in England and Spain. In: DICKINSON, A.; GORDON P.; LEE, P. J. (Ed.). Raising Standards in History Education: v. 3. International Review of History Education. London: Woburn Press, 2001. p. 116-45.

CHAPMAN, A. Accounting for Interpretations / Interpreting Accounts. Unpublished EdD Institution Focused Study, Institute of Education, University of London, 2001.

CHAPMAN, A. Towards an Interpretations Heuristic: A case study exploration of 16-19 year old students' ideas about explaining variations in historical accounts. Unpublished EdD thesis, Institute of Education, University of London, 2009.

CROSBY, A. Ecological Imperialism. The biological expasion of Europe - 900-1900. Cambridge (UK): Cambridge University Press, 1986.

DAVIES, N. The Isles: A History. London: Macmillan, 1999.

DIAMOND, J. Guns, Germs and Steel. London: Jonathan Cape, 1997.

DICKINSON, A. K. What should history be? In: KENT, A. (Ed.). School Subject Teaching: the History and Future of the Curriculum. London: Kogan Page, 2000. p. 86-110.

DICKINSON, A. K.; LEE, P. J. Understanding and Research. In: DICKINSON A. K.; LEE, P. J. (Ed.). History Teaching and Historical Understanding. London: Heinemann Educational Books, 1978. p. 94-120.

DICKINSON, A. K.; LEE, P. J. Making sense of history. In: DICKINSON, A. K.; LEE, P. J.; ROGERS, P. J. (Ed.). Learning History. London: Heinemann Educational Books, 1984. 
DONOVAN, M. S.; BRANSFORD J. D.; PELlEGRINO, J. W. (Ed.). How People Learn: Bridging Research and Practice. Washington DC: National Academy Press, 1999. p. 117-153.

DUVENAGE P. (Ed.). Studies in Metahistory. Pretoria: Human Sciences Research Council, 1993.

ENGELS, F. (1845). The Condition of the Working Class in England. Retrieved October, v. 15, 2010, from Marx/Engels Internet Archive: <http://www.marxists.org/archive/marx/ works/1845/condition-working-class/ch07.htm>. Acesso em: 23 abr. 2012.

EPSTEIN, T. History and Racial Identity in an Urban High School. Retrieved October, v. 13, 2010, from American Historical Association, Perspectives, Teaching Column, 2001: $<$ http://www.historians.org/perspectives/issues/2001/0112/0112tec1.cfm>. Acesso em: 25 jun. 2012.

FOSTER, S. J.; CRAWFORD, K. A. (Ed.). What shall we tell the children: international perspectives on school history textbooks. Greenwich CT: Information Age Publishing, 2006.

GAGO, M. Children's understanding of historical narrative in Portugal. In: ASHBY, R.; GORDON, P.; LEE, P. J. (Ed.). Understanding History - Recent Research in History Education: v. 4. International Review of History Education. London: Routledge Falmer, 2005. p. 83-97.

GUNNING, D. The Teaching of History. London: Croom Helm, 1978.

HALLDÉN, O. Constructing the Learning Task in History instruction. In: CARRETERO, M.; VOSS, J. E. (Ed.). Cognitive and Instructional Processes in History and the Social Sciences. Hillsdale, New Jersey: Lawrence Erlbaum Associates, 1994. p. 187-200.

HSIAO, Y. Taiwanese Students' Understanding of Differences in Textbook Accounts. In: ASHBY, R.; GORDON, P.; LEE, P. J. (Ed.). Understanding History - Recent Research in History Education: v. 4. International Review of History Education. London: Routledge Falmer, 2005. p. 54-67.

KOULOURI, C. (Ed.). Clio in the Balkans: The Politics of History Education. Thessaloniki: Center for Democracy and Reconciliation in Southeast Europe, 2002.

KUHN, T. S. The Structure of Scientific Revolutions. Chicago: University of Chicago Press, 1998.

LEE, P. J. Explanation and Understanding in History. In: DICKINSON, A. K.; LEE, P. J. (Ed.). History Teaching and Historical Understanding. London: Heinemann Educational Books, 1978. p. 72-93.

LEE, P. Why learn history? In: DICKINSON, A.; LEE, P.; ROGERS, P. (Eds.). Learning History. London: Heinemann, 1984. p. 98-126. 
LEE, P. J. History in School: Aims, Purposes and Approaches: a Reply to John White. In: LEE, P.; SLATER, J.; WALSH, P.; WHITE, J. (Ed.). The Aims of School History: The National Curriculum and Beyond. London: Tufnell Press, 1992. p. 20-34.

LEE, P. J. (2004). 'Walking backwards into tomorrow': Historical consciousness and understanding history. International Journal of Historical Learning Teaching and Research, v. 4, n. 1, Retrieved October 12, 2010, from: <http://centres.exeter.ac.uk/historyresource/ journal13/archive.htm>. Acesso em: 2012.

LEE, P. J. Putting principles into practice: understanding history. In: BRANSFORD, J. D.; DONOVAN, M. S. (Ed.) How Students Learn: History, Math and Science in the Classroom. Washington, DC: National Academy Press, 2005. p. 31-77.

LEE P. J.; ASHBY, R. Progression in historical understanding among students ages 7-14. In: SEIXAS, P.; STEARNS, P.; WINEBURG, S. (Ed.). Knowing, Teaching and Learning History: National and International Perspectives. New York and London: New York Press, 2000. p. 199-222.

LEE, P. J.; ASHBY, R. Empathy, perspective taking, and rational understanding. In: DAVIS Jr., O. L.; FOSTER, S.; YEAGER, E. (Ed.). Historical Empathy and Perspective Taking in the Social Studies. Boulder: Rowman and Littlefield, 2001. p. 21-50.

LEE, P. J.; ASHBY R.; DICKINSON, A. K. Just Another Emperor: Understanding Action in the Past. International Journal of Educational Research, v. 27, n. 3, p. 233-244, 1997.

LEE, P. J.; DICKINSON, A. K.; ASHBY, R. Progression in children's ideas about history. In: HUGHES, M. (Ed.). Progression in Learning (BERA Dialogues). Clevedon, Bristol (PA) and Adelaide: Multilingual Matters, 1996, p. 50-81.

LEE, P. J.; DICKINSON, A. K.; MAY, D.; SHEMILT, D. Youth and History: some initial conceptualizations and analyses of the British and Scottish data. In: ANGVIK, M.; BORRIES, B. von (Ed.). Youth and History: A comparative survey on historical consciousness and political attitudes among adolescents, v. A: Description. Hamburg: Körber-Stiftung, 1997. p. 377-87.

LEE, P. J.; HOWSON, J. 'Two out of five did not know that Henry VIII had six wives': History education, historical literacy and historical consciousness. In: SYMCOX, L.; WILSCHUT, A. (Ed.). National history standards - The problem of the canon and the future of teaching history: v. 5. International Review of History Education. Charlotte: Information Age Publishing, 2009. p. 211-361.

LEE, P. J.; SHEMILT, D. A scaffold, not a cage: Progression and progression models in history. Teaching History, v. 113, p. 13-23, 2003.

LEE, P. J.; SHEMILT, D. 'I just wish we could go back in the past and find out what really happened': Progression in understanding about historical accounts. Teaching History, v. 117, p. 25-31, 2004. 
LEE, P. J.; SHEMILT, D. Is any explanation better than none? Over-determined narratives, senseless agencies and one-way streets in students' learning about cause and consequence in history. Teaching History, v. 137, p. 42-49, 2009.

LEE, P.; SLATER, J.; WALSH, P.; WHITE, J. The Aims of School History: The National Curriculum and Beyond. London: Tufnell Press, 1992.

MACINTOSH, H. G. Testing Skills in History. In: PORTAL, C. (Ed.). The History Curriculum for Teachers. Lewes: Falmer Press, 1983. p. 183-219.

McNEILL, J. R.; McNEILL, W. The Human Web: A Bird's-Eye View of Human History. New York: Norton, 2003.

MEGILL, A. Jörn Rüsen's Theory of Historiography. History and Theory, v. 33, n. 1, p. 39-60, 1986.

MEGILL, A. Historical Knowledge, Historical Error: A Contemporary Guide to Practice. Chicago: University of Chicago Press, 2007.

NAKOU, I. Children's Historical Thinking within a Museum Environment: An Overall Picture of a Longitudinal Study. In: DICKINSON, A.; GORDON, P.; LEE, P. J. (Ed.). Raising standards in history education: v. 3. International Review of History Education. London: Woburn Press, 2001. p. 73-96.

NUNN, N. Shackled to the Past: The Causes and Consequences of Africa's Slave Trades. In: DIAMOND, J.; ROBINSON, J. A. (Ed.). Natural Experiments of History. Cambridge Massachusetts: Belknap Press of Harvard University Press, 2010. p. 142-84.

RODGER, N. A. M. The Safeguard of the Sea. London: Harper Collins, 1997.

RODGER, N. A. M. The Command of the Ocean. London: Allen Lane, 2004.

RÜSEN, J. Paradigm shift and theoretical reflection in Western German historical studies. In: DUVENAGE, P. (Ed.). Studies in Metahistory. Pretoria: Human Sciences Research Council, 1993. p. 161-86.

SEIXAS, P. Popular Film and Young People's Understanding of the History of Native-White Relations. The History Teacher, v. 26, n. 3, p. 351-70, 1993.

SHEMILT, D. Preface. In: LEE, P.; SLATER, J.; WALSH, P.; WHITE, J. The Aims of School History: The National Curriculum and Beyond. London: Tufnell Press, 1962. p. $1-8$.

SHEMILT, D. History 13-16 Evaluation Study. Edinburgh: Holmes McDougall, 1980.

SHEMILT, D. The Devil's Locomotive. History and Theory XXII, v. 4, p. 1-18, 1983.

SHEMILT, D. Beauty and the Philosopher: Empathy in History and Classroom. In: DICKINSON, A. K.; LEE, P. J.; ROGERS, P. J. (Ed.). Learning History. London: Heinemann Educational Books, 1984. p. 39-84. 
SHEMILT, D. Adolescent Ideas about Evidence and Methodology in History. In: PORTAL, C. The History Curriculum for Teachers. Lewes: Falmer Press, 1987. p. 39-61.

SHEMILT, D. Drinking an ocean and pissing a cupful: How adolescents make sense of history. In: SYMCOX, L.; WILSCHUT, A. (Ed.). National history standards - The problem of the canon and the future of teaching history: v. 5. International Review of History Education. Charlotte: Information Age Publishing. 2009, p. 141-210.

TOULMIN, S.; GOODFIELD, J. The Discovery of Time. London: Hutchinson, 1965.

TRAILLE, E. K. School History and Perspectives on the Past: A Study of Students of African-Caribbean Descent and Their Mothers. Unpublished EdD thesis, Institute of Education, University of London, 2006.

VOSS J. F.; CARRETERO, M.; KENNET, J.; SILFIES, L. N. The collapse of the Soviet Union: A case study in causal reasoning. In: CARRETERO, M.; VOSS, J. F. (Ed.). Cognitive and Instructional Processes in History and the Social Sciences. Hillsdale: Lawrence Erlbaum, 1994. p. 403-430.

VOSS, J. F.; CIARROCHI, J.; CARRETERO, M. Causality in history: On the 'intuitive' understanding of the concepts of sufficiency and necessity. In: VOSS, J. F.; CARRETERO, M. (Ed.). Learning and Reasoning in History: v. 2. International Review of History Education. London: Woburn Press, 1998. p. 199-213.

WALSH, W. H. An Introduction to the Philosophy of History. London: Hutchinson University Library, 1967.

WERTSCH, J. Specific Narratives and Schematic Narrative Templates. In: SEIXAS, P. (Ed.). Theorizing Historical Consciousness. Toronto: University of Toronto Press, 2004. p. 49-62.

WERTSCH, J. V.; ROZIN, M. The Russian Revolution: official and unofficial accounts. In: VOSS, J. F.; CARRETERO, M. (Ed.). Learning and Reasoning in History: v. 2. International Review of History Education. London: Woburn Press, 1998. p. 39-60.

WHITE, J. The purpose of school history: Has the National Curriculum got it right?. In: LEE, P.; SLATER, J.; WALSH, P.; WHITE, J. The Aims of School History: The National Curriculum and Beyond. London: Tufnell Press, 1992. p. 9-19.

WILSCHUT, A. Canonical standards or orientational frames of reference? The cultural and educational approach to the debate about standards in history teaching. In: SYMCOX, L.; WILSCHUT, A. (Ed.). National history standards- The problem of the canon and the future of teaching history: v. 5. International Review of History Education. Charlotte: Information Age Publishing, 2009. p. 117-40.

WINEBURG, S. 'Making Historical Sense.' In: SEIXAS, P.; STEARNS, P.; WINEBURG, S. (Ed.). Teaching, Learning and Knowing History. New York: New York University Press. Wineburg, S. S., 2000. p. 306-325. 
WINEBURG, S. Historical Thinking and Other Unnatural Acts. In: WINEBURG, S. S. (Ed.). Historical Thinking and Other Unnatural Acts. Philadelphia: Temple University Press. Wineburg, S. S., 2001a. p. 3-27.

WINEBURG, S. On the Reading of Historical Texts: Notes on the Breach Between School and Academy. In: WINEBURG, S. S. (Ed.). Historical Thinking and Other Unnatural Acts. Philadelphia: Temple University Press, 2001b. p. 63-88.

Texto recebido em 21 de março de 2016. Texto aprovado em 27 de março de 2016. 